\title{
Ependymal Vps35 Promotes Ependymal Cell Differentiation and Survival, Suppresses Microglial Activation, and Prevents Neonatal Hydrocephalus
}

\author{
Kong-yan Wu, ${ }^{1}$ Fu-lei Tang, ${ }^{2}$ Daehoon Lee, ${ }^{1}$ Yang Zhao, ${ }^{1,3}$ Hyunjin Song, ${ }^{2}{ }^{\oplus}$ Xiao-Juan Zhu, ${ }^{3}{ }^{\circledR}$ Lin Mei, ${ }^{1,2,4}$ and \\ (D) Wen-Cheng Xiong ${ }^{1,2,4}$ \\ ${ }^{1}$ Department of Neurosciences, School of Medicine, Case Western Reserve University, Cleveland, Ohio 44106, ${ }^{2}$ Department of Neuroscience and \\ Regenerative Medicine, Medical College of Georgia, Augusta University, Augusta, Georgia 30912, ${ }^{3}$ Key Laboratory of Molecular Epigenetics of \\ Ministry of Education, Institute of Cytology and Genetics, Northeast Normal University, Changchun, Jilin 130024, China, and ${ }^{4}$ Louis Stokes \\ Cleveland Veterans Affairs Medical Center, Cleveland, Ohio 44106
}

Hydrocephalus is a pathologic condition associated with various brain diseases, including Alzheimer's disease (AD). Dysfunctional ependymal cells (EpCs) are believed to contribute to the development of hydrocephalus. It is thus of interest to investigate EpCs' development and function. Here, we report that vacuolar protein sorting-associated protein 35 (VPS35) is critical for EpC differentiation, ciliogenesis, and survival, and thus preventing neonatal hydrocephalus. VPS35 is abundantly expressed in EpCs. Mice with conditional knock-out (cKO) of Vps35 in embryonic (Vps35 ${ }^{\text {GFAP-Cre }}$ and Vps35 ${ }^{\text {Emxl-Cre }}$ ) or postnatal (Vps35 ${ }^{\text {Foxil-CreER }}$ ) EpC progenitors exhibit enlarged lateral ventricles (LVs) and hydrocephalus-like pathology. Further studies reveal marked reductions in EpCs and their cilia in both Vps35 ${ }^{\text {GFAP-Cre }}$ and Vps35 $5^{\text {Foxjl-CreER }}$ mutant mice. The reduced EpCs appear to be due to impairments in EpC differentiation and survival. Additionally, both Vps $35^{\text {GFAP-Cre }}$ and Vps $35^{\text {Foxjl-CreER }}$ neonatal pups exhibit increased cell proliferation and death largely in a region close to LV-EpCs. Many microglia close to the mutant LV-EpC region become activated. Depletion of the microglia by PLX3397, an antagonist of colony-stimulating factor 1 receptor (CSF1R), restores LV-EpCs and diminishes the pathology of neonatal hydrocephalus in Vps $35^{\text {Foxjl-CreER }}$ mice. Taken together, these observations suggest unrecognized functions of $\mathrm{Vps} 35$ in $\mathrm{EpC}$ differentiation, ciliogenesis, and survival in neonatal $\mathrm{LV}$, and reveal pathologic roles of locally activated microglia in $\mathrm{EpC}$ homeostasis and hydrocephalus development.

Key words: ciliogenesis; ependymal cells; hydrocephalus; microglia; VPS35

Significance Statement

This study reports critical functions of vacuolar protein sorting-associated protein 35 (VPS35) not only in promoting ependymal cell (EpC) differentiation, ciliogenesis, and survival, but also in preventing local microglial activation. The dysfunctional EpCs and activated microglia are likely to induce hydrocephalus.

\section{Introduction}

Hydrocephalus is a pathologic condition with abnormal buildup of CSF in the ventricles of the brain, which could result in intellectual and motor deficits (Tully and Dobyns, 2014; Kousi and

\footnotetext{
Received June 27, 2019; revised Mar. 30, 2020; accepted Apr. 2, 2020.

Author contributions: K.-y.W., F.-I.T., L.M., and W.-C.X. designed research; K.-y.W., F.-I.T., D.L., Y.Z., and H. S. performed research; K.-y.W., F.-I.T., D.L., H.S., X.-J.Z., L.M., and W.-C.X. contributed unpublished reagents/ analytic tools; K.-y.W., D.L., Y.Z., L.M., and W.-C.X. analyzed data; K.-y.W., D.L., and W.-C.X. wrote the paper.

K.-y.W., F.-I.T., and D.L. contributed equally to this work.

This work was supported by grants from National Institute on Aging and National Institutes of Health (AG045781; to W.-C.X.)

The authors declare no competing financial interests.

Acknowledgements: We thank members of the Dr. Xiong and Dr. Mei laboratories for discussion.

Correspondence should be addressed to Wen-Cheng Xiong at wen-cheng.xiong@case.edu.

https://doi.org/10.1523/JNEUROSCI.1520-19.2020

Copyright ( $\odot 2020$ the authors
}

Katsanis, 2016). Etiologically, hydrocephalus can be congenital or acquired. The congenital hydrocephalus is present at birth and may be caused by genetic abnormalities during fetal development, while the acquired hydrocephalus can occur at all ages of life and may be induced by various factors. Interestingly, hydrocephalus-like pathology [e.g., normal pressure of hydrocephalus $(\mathrm{NPH})]$ is often detected in patients with Alzheimer's disease (AD; Shprecher et al., 2008), the most common form of neurodegenerative diseases.

Histologically, hydrocephalus can be classified into communicating or non-communicating type, based on the CSF flow. CSF, mainly produced in choroid plexus, is transported from lateral ventricle $(\mathrm{LV})$ to third ventricle $(3 \mathrm{~V})$, aqueduct $(\mathrm{Aq})$, and fourth ventricle $(4 \mathrm{~V})$, and then reabsorbed in the subarachnoid space (Fliegauf et al., 2007; Louvi and Grove, 2011). Stenosis of Aq of sylvius is a major cause for non-communicating 
hydrocephalus (Fliegauf et al., 2007; Kahle et al., 2016). Defects in ciliary polarization and beating, and ependymal cell (EpC) adhesion and maintenance result in communicating hydrocephalus in adult mice (Guirao et al., 2010; Ohata et al., 2014; O'Leary et al., 2017; Shimada et al., 2017). However, the mechanisms underlying neonatal hydrocephalus remain obscure.

EpCs, the major multiciliated cell type lining ventricles, play essential roles in CSF circulation and homeostasis (Del Bigio, 2010). The majority of mouse EpC precursors are derived from radial glial cells (RGCs) around embryonic day (E) 14 to E16, and then differentiated and matured with cilia formation in neonatal age (Spassky et al., 2005; Louvi and Grove, 2011; Fuentealba et al., 2015). In addition to EpCs, type B1 progenitor cells, also called neural stem cells (NSCs), are derived from RGCs shortly after birth (Voigt, 1989; Doetsch et al., 1999; Spassky et al., 2005; Fuentealba et al., 2015). Both EpCs and B1 cells constitute pinwheel organization of LV surface (Mirzadeh et al., 2008).

Vacuolar protein sorting-associated protein 35 (VPS35), a key component of retromer complex, plays a critical role in retrieval of transmembrane proteins or cargos from endosomes to the trans-Golgi network or recycling cargos from endosomes to cell surface (Hierro et al., 2007; Collins, 2008; Harbour et al., 2010; Seaman, 2012; Burd and Cullen, 2014; Vagnozzi and Praticò, 2019). Retromer- or VPS35 deficiency appears to be a risk factor for neurodegenerative diseases, including $\mathrm{AD}$ and Parkinson's disease (PD; Small and Petsko, 2015). Mutations in vps35 gene have been identified in patients with autosomal dominant PD (Deutschlander et al., 1993; Vilarino-Guell, 2011; Zimprich et al., 2011; Tsika et al., 2014; Wang et al., 2016a; Williams et al., 2017) or early onset AD (Rovelet-Lecrux et al., 2015). Vps35/retromer-loss in mouse models results in PD-like deficits as well as enhanced AD-like neuropathology in Tg2576, an AD mouse model (Wen et al., 2011; Zimprich et al., 2011; Tang et al., 2015a,b; Wang et al., 2016a). Vps35 plays important roles in various types of brain cells, including pyramidal neurons, dopamine neurons, and microglia (Wen et al., 2011; Wang et al., 2012; Tang et al., 2015a,b; Appel et al., 2018). However, its function in EpCs remains to be exploited.

Here, we report that Vps35 in EpCs is necessary for EpC differentiation, ciliogenesis, and maintenance. VPS35 is expressed in EpCs. Mice with conditional knock-out (cKO) of $\mathrm{Vps} 35$ in embryonic (e.g., $\mathrm{Vps} 35^{\mathrm{GFAP}-\mathrm{Cre}}$ ) or postnatal (e.g., Vps35 ${ }^{\text {Foxj1-CreER }}$ ) progenitors of EpCs show features of neonatal hydrocephalus, including loss of $\mathrm{S} 100 \beta^{+}$EpCs, defective EpC ciliogenesis, and enlarged LVs. Additionally, both Vps $35^{\text {GFAP-Cre }}$ and Vps35 $5^{\text {Foxj1-CreER }}$ mutant mice at postnatal day (P)5 show impaired EpC differentiation and increased cell proliferation and death in LV-subventricular zone (SVZ) region. Whereas both Vps35 $5^{\text {GFAP-Cre }}$ and Vps $35^{\text {Foxj1-CreER }}$ mutant mice show similar phenotypes during EpC development, there are few differences. Vps35 $5^{\text {GFAP-Cre }}$, but not $\mathrm{Vps} 35^{\text {Foxj1-CreER }}$, mice (at P5) display an increase in EpC death. Vps35 ${ }^{\text {Foxj1-CreER }}$, but not Vps35 GFAP-Cre, mice show an increase in Foxj1-Cre ${ }^{+}$cells with unknown cellular identify. Remarkably, microglia in LV-SVZ and LV-EpC regions are activated in $\mathrm{Vps} 35^{\text {Foxj1-CreER }}$ mice, and depletion of microglia by PLX3397 restores EpCs and diminishes hydrocephalus pathology. These results suggest that the ependymal Vps35 not only promotes EpC differentiation in a cell autonomous manner, but also prevents microglial activation and RGC or EpC precursor cell proliferation and death in a cell non-autonomous manner.

\section{Materials and Methods}

Animals

Vps35 floxed $\left(\mathrm{Vps} 35^{\mathrm{f} / \mathrm{f}}\right)$ mice were generated, genotyped, and maintained as described previously (Tang et al., 2015b; Appel et al., 2018). GFAP-Cre mice (stock 004600), Emx1-Cre (stock 005628), and

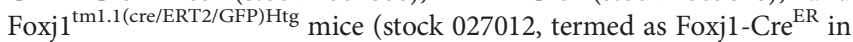
this study) were purchased from The Jackson Laboratory. NeuroD6-Cre (also called Nex-Cre) mice were kindly provided by Klaus-Armin Nave (Goebbels et al., 2006). Vps35 $5^{\mathrm{f} / \mathrm{f}}$ mouse line was crossed with GFAP-Cre, Emx1-Cre, NeuroD6-Cre, or Foxj1-Cre ${ }^{\mathrm{ER}}$ mouse lines to generate Vps35 homozygous mutant Vps35 ${ }^{\text {GFAP-Cre }}$, Vps35 ${ }^{\text {Emxl-Cre }}$, Vps35NeuroD6-Cre or Vps35 ${ }^{\text {Foxjl-CreER }}$, respectively. Ai9 (stock 007909, The Jackson Laboratory) mice were also crossed with indicated Cre lines to report Cre activity. To induce Cre activity in Foxj1-Cre ${ }^{\mathrm{ER}}$ mice, tamoxifen $(75 \mathrm{mg} / \mathrm{kg})$ was injected into the mother mice or pups subcutaneously injected for $5 \mathrm{~d}$, and their pups, which were exposed to tamoxifen, were examined. All of the mouse lines indicated above were maintained in C57BL/6 background for more than six generations. Mice were housed in $12 / 12 \mathrm{~h}$ light/dark cycle animal rooms in Case Western Reserve University. Both male and female mice were examined throughout all the experiments. All experimental procedures were approved by the Institutional Animal Care and Use Committees of Case Western Reserve University, and in accordance with the National Institutes of Health guidelines.

\section{Antibodies and reagents}

Antibodies to 5-bromo-2'-deoxyuridine (BrdU; Abcam, ab6326), $\beta$-catenin (Abcam, ab6302-100), CD11b (Abcam, ab8227), CD133 (Invitrogen, 14133182), cleaved Caspase 3 (Cell Signaling, 9579), Vps35 antibody (Abcam, ab10099), DsRed (Clontech, 632496), GFAP (Novus Biologicals, NBP1-05,198), GAPDH (Abcam, ab8245), Iba1 (Abcam, ab5076), Ki67 (Abcam, ab16667), NeuN (Neuromics, Mo 22 122), S100 $\beta$ (Abcam, ab868), SOX2 (Santa Cruz biotechnology), acetylated tubulin (ace-tub; Sigma, T6793), and $\gamma$-tubulin ( $\gamma$-tub; Sigma, T6557) were purchased. All secondary antibodies were purchased from Jackson ImmunoResearch. In addition, the following reagents, in situ cell death detection kit (POD; Roche, 11684817910), BrdU (Millipore 19-160), EdU (GeneCopoeia, A009), PLX3397 (MedChemExpress, HY-16749), cresyl violet acetate (Sigma, C5042), and tamoxifen (Sigma, T5648) were used.

\section{Tissue processing and immunofluorescence}

Mice with indicated genotypes were perfused, the brains were dissociated and then postfixed in $4 \%$ paraformaldehyde (PFA; pH7.4) overnight. The brains were cryoprotected in PBS containing 30\% sucrose and embedded in O.C.T for sectioning with cryostat microtome at the thickness of $30 \mu \mathrm{m}$. The mouse brain sections were washed with PBS, followed by incubation in $0.3 \%$ Triton X-100 for $30 \mathrm{~min}$ at room temperature. The sections were then incubated in primary antibodies at $4^{\circ} \mathrm{C}$ overnight after blocked with 10\% donkey serum. Alexa Fluor 405/488/ 593/647-conjugated secondary antibodies were applied to sections for 2 $\mathrm{h}$ at room temperature. In some conditions, DAPI was also incubated with sections to reveal cell nuclei. After washed with PBS, mouse brain sections were mounted for confocal imaging with Zeiss LSM 800 system.

\section{Nissl and $\beta$-galactosidase ( $\beta$-gal) staining}

Vibratome sections of mouse brains were mounted and air dried. The sections were rinsed in PBS for $5 \mathrm{~min}$, and then stained in $0.1 \%$ cresyl violet solution for 5-10 $\mathrm{min}$. The sections were quickly rinsed in distilled water and dehydrated in $70 \%, 80 \%, 90 \%$ ethanol for $2-3$ min step by step. After differentiated in $95 \%$ ethanol, the sections were dehydrated in $100 \%$ ethanol for $2-5 \mathrm{~min}$. The sections were cleared with xylene for $2-$ 5 min, mounted with DPX Mountant (Sigma-Aldrich, 44581) for histology and dried in fume hood. For LacZ staining, mouse brain slices were fixed with $0.5 \%$ glutaraldehyde, then incubated in X-gal solution overnight at $37^{\circ} \mathrm{C}$, as described previously (Wen et al., 2011). The mounted sections were captured with KEYENCE BZX microscope.

\section{$B r d U, E d U$, and PLX 3397 injections}

BrdU, EdU, and PLX3397 were subcutaneously injected with a $0.5-\mathrm{ml}$ syringe (BD). For BrdU/EdU injections, BrdU $(10 \mathrm{mg} / \mathrm{ml})$ or $\mathrm{EdU}$ 
A

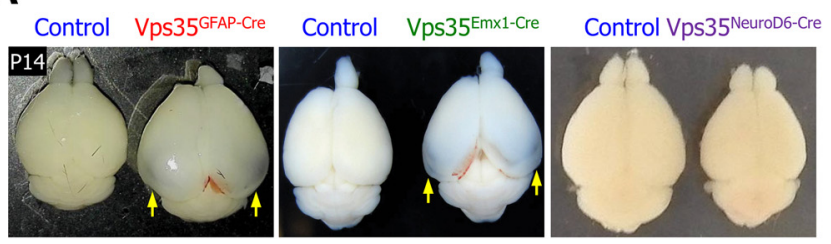

B

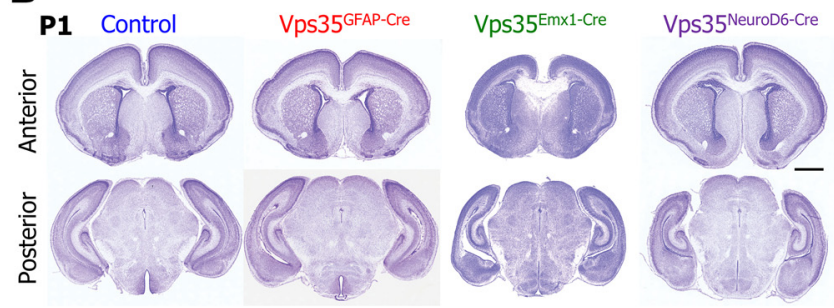

D

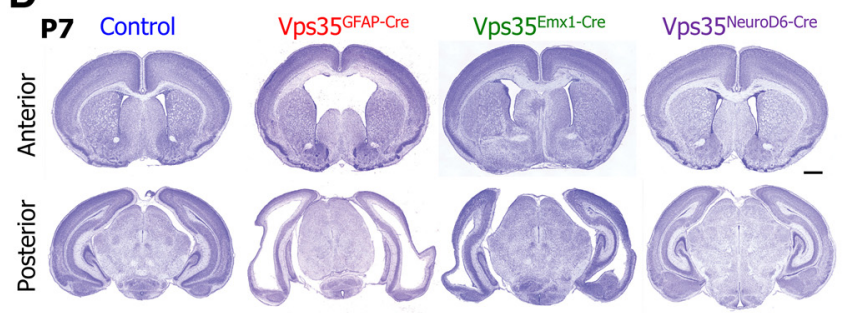

H

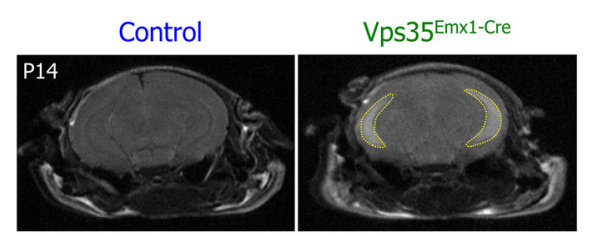

I

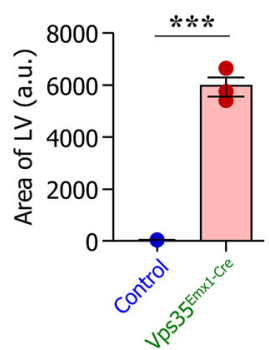

C

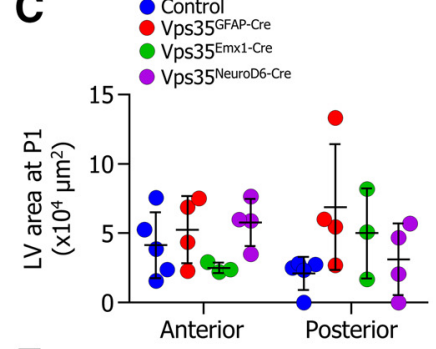

E

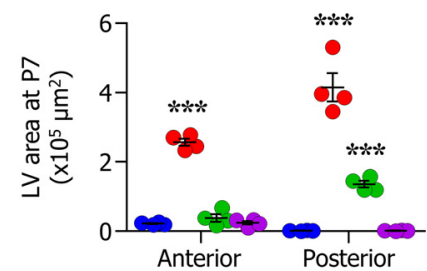

F

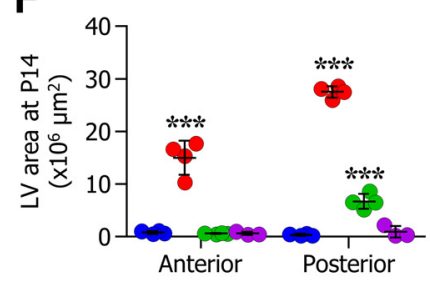

G

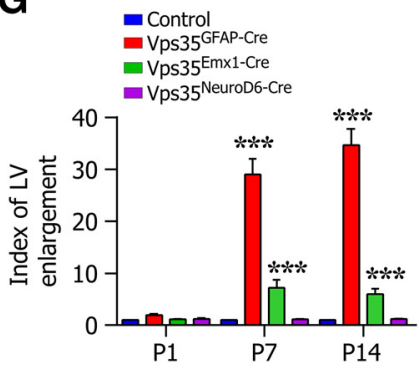

Figure 1. Neonatal hydrocephalus in Vps $35^{\text {GFAP-Cre }}$ and Vps $35^{\text {Emx1-Cre }}$, but not Vps $35^{\text {Neurod6-Cre }}$, mice. $\boldsymbol{A}$, Representative images showing brain size of mice with indicated genotypes. Arrows indicate transparent brain regions. $\boldsymbol{B}$, Nissl staining images of P1 brain slices from mice with indicated genotypes. Slices at anterior and posterior levels are shown. Scale bar, $1000 \mu \mathrm{m}$. $\boldsymbol{C}$, Quantification of anterior and posterior areas of LV from P1 control, Vps $35^{\text {GFAP-Cre }}, V_{p s} 35^{\text {Emx1-Cre }}$, and Vps $35^{\text {NeuroDb-Cre }}$ mice. Data shown are mean \pm SEM from five control, four Vps $35^{\text {GFAP-Cre }}$, three Vps35 $5^{\text {Emx1-Cre }}$, and four Vps35 $3^{\text {NeuroD6-Cre }}$ mice. ns, no significance, one-way ANOVA with Tukey's HSD post hoc test. D, Nissl staining of P7 brain slices from mice with indicated genotypes. Scale bar, $1000 \mu \mathrm{m}$. $\boldsymbol{E}$, Quantification of LV areas in P7 mouse brains. Data shown are mean \pm SEM from four mice of each group; ${ }^{* * *} p<0.001$, ns, no significance, one-way ANOVA with Tukey's HSD post hoc test. $\boldsymbol{F}$, Quantification of LV areas in P14 mouse brains. Data shown are mean \pm SEM from three to four mice of each group; ${ }^{* * *} p<0.001$, ns, no significance, one-way ANOVA with Tukey's HSD post hoc test. G, Index for LV enlargement from Vps35 $5^{\text {GFAP-Cre }}$, Vps35 $5^{\text {Emx1-Cre }}$, and Vps35 $5^{\text {NeuroD6-Cre }}$ mice at indicated postnatal ages. The index values are calculated as: (anterior + posterior LV area)/(anterior + posterior LV area of control group). Data shown are mean \pm SEM from three to four mice of each group at each postnatal age. $\boldsymbol{H}$, MRI images showing brain and LV structures of control and Vps35 $5^{\text {Emx1-Cre }}$ mice at P14. The location on rostral-caudal axis is at bregma -2.92 . The regions with high intensity in Vps35 $5^{\text {Emx1-Cre }}$ mouse brain are highlighted in yellow dotted lines, indicating LV hydrocephalus. I, Quantification of LV area of mouse brains based on MRI images. Data shown are mean \pm SEM $(n=3)$; ${ }^{* * *} p<0.001$, Student's $t$ test.

$(10 \mathrm{mg} / \mathrm{ml})$ in PBS was injected at the dose of $50 \mathrm{mg} / \mathrm{kg}$ body weight, 2-4 h later, the mice were killed for experimental analysis. PLX3397 was dissolved in dimethylsulfoxide (DMSO) at the concentration of $8 \mathrm{mg} / \mathrm{ml}$, and the mice were given subcutaneous injections at the dose of $20 \mathrm{mg} / \mathrm{kg}$ body weight three times at P2, P4, and P6, respectively, and killed at P7. Equal amount of DMSO was used as mock control injection.

\section{LV medial wall dissociation and whole-mount immunostaining}

P7 or P10 mice were anesthetized and killed, and their brains were dissociated and placed into $10-\mathrm{cm}$ Petri dish containing cold HBSS on ice. Along the interhemispheric fissure, mouse brain was cut into two hemispheres, then two coronal cuts were made, one was at the rostral region to dissect olfactory bulbs away, the other one was at the most posterior region to expose the caudal hippocampus. The posterior two thirds of hippocampus was cut off, the cortex covering this region was carefully peeled away to expose LV (Mirzadeh et al., 2008). The corpus callosum was dissected to separate LV dorsally, then the medial wall covering lateral septal nuclei was dissociated from the remaining hemisphere. The whole mounts of LV medial walls were fixed in $4 \%$ PFA overnight. After washed with PBS for three times, the whole mounts were incubated in $2 \%$ Triton X-100 for $2 \mathrm{~h}$ at room temperature. Primary antibodies were applied to whole mounts for $48 \mathrm{~h}$, followed by corresponding secondary antibodies. The whole mounts were mounted in wells with 200- to 300$\mu \mathrm{m}$ height on glass slide for imaging.

\section{Imaging and statistical analyses}

Mounted samples were imaged by Zeiss LSM 800 confocal microscopy system or KEYENCE BZX microscope. Images were processed with ImageJ $1.51 \mathrm{n}$ software (National Institutes of Health). 
A

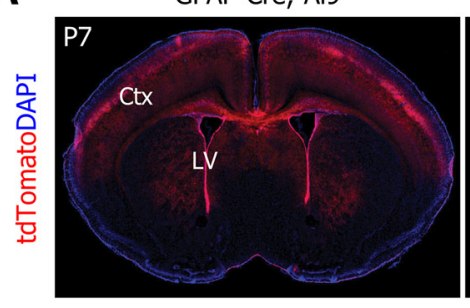

B

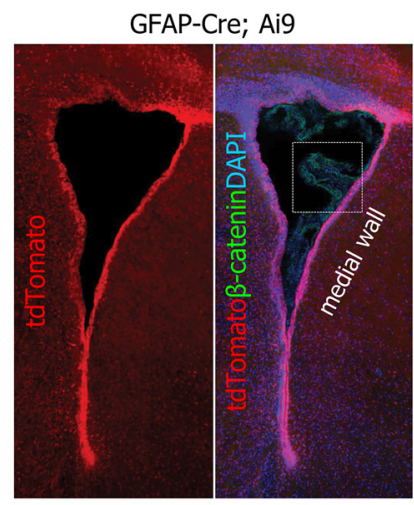

C

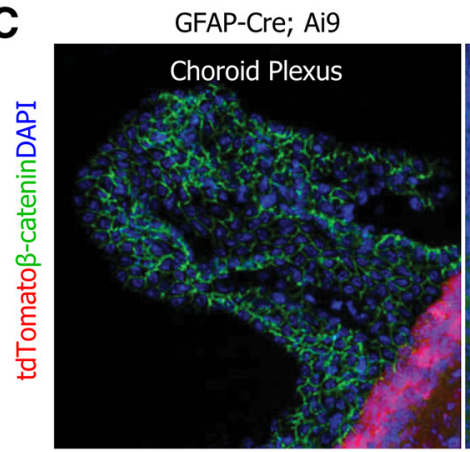

Emx1-Cre; Ai9

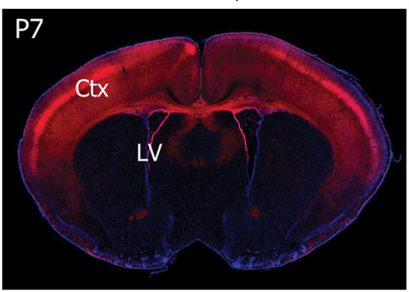

Emx1-Cre; Ai9

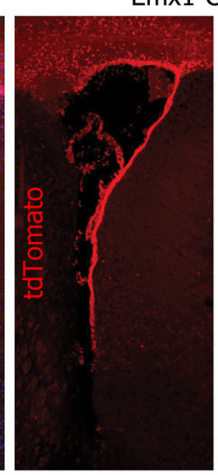

NeuroD6-Cre; Ai9

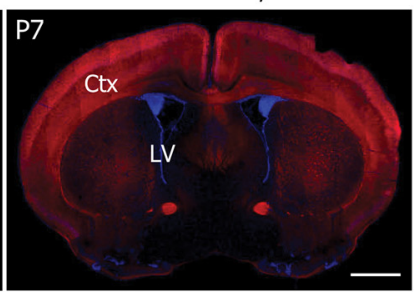

NeuroD6-Cre; Ai9

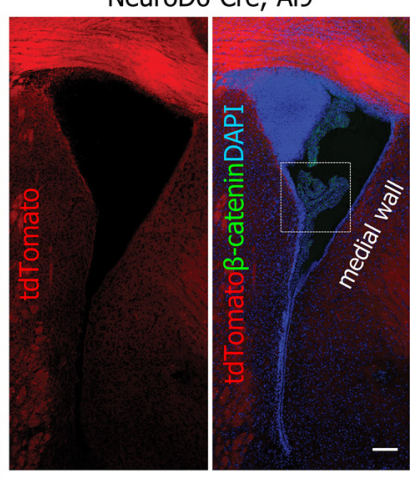

NeuroD6-Cre; Ai9

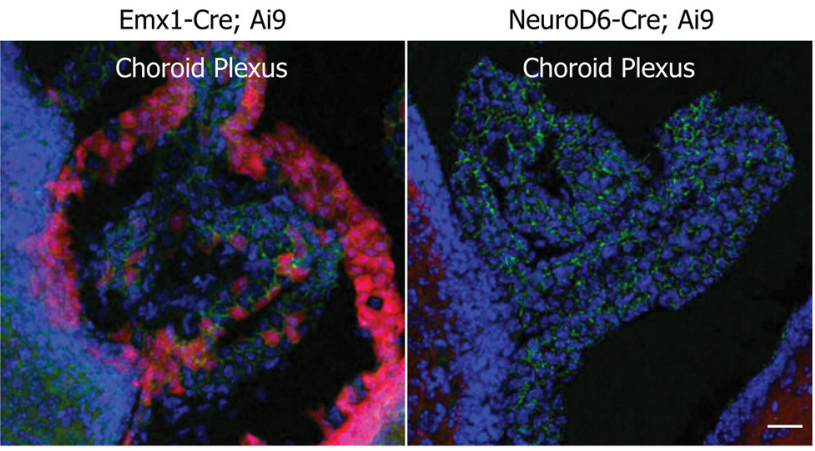

Figure 2. Cre recombinase activity in GFAP-Cre, Emx1-Cre, and Neurod6-Cre mouse lines. $\boldsymbol{A}, \boldsymbol{B}$, Representative td ${ }^{+}$fluorescence images of mouse brain sections from GFAP-Cre; Ai9, Emx1Cre; Ai9, and NeuroD6-Cre; Ai9 mice at age of P7. Note that Ai9 is a Cre activity reporter mouse line, whose td fluorescence depends the Cre recombinase activity. Ctx: cortex. In $\boldsymbol{B}$, the brain slices were costained td (red) with $\beta$-catenin (green) and DAPI (blue); the regions within white square indicate choroid plexus. Scale bars, $1000 \mu \mathrm{m}(\boldsymbol{A})$ and $100 \mu \mathrm{m}(\boldsymbol{B})$. $\boldsymbol{C}$, Magnification of choroid plexus regions in $\boldsymbol{B}$. Scale bar, $20 \mu \mathrm{m}$. GFAP-Cre and Neurod6-Cre are not expressed in choroid plexus, while Emx1-Cre is expressed in choroid plexus.

Experimental design and statistical analysis

All experiments were carried with corresponding control groups, including mouse genetics control, experimental control. All of these control groups were clearly labeled in figures and described in Results. The statistical analysis was evaluated by ANOVA with post hoc or Student's $t$ tests. The values of mean \pm SEM were presented. The $n$ numbers can be found in the figure legends. Statistical significance was defined as $p<0.05$.

\section{Results}

Hydrocephalus-like pathology in neonatal Vps $35^{\text {GFAP-Cre }}$ and Vps35 ${ }^{\text {Emx1-Cre }}$, but not Vps35 ${ }^{\text {NeuroD6-Cre }}$, mice

To investigate Vps35's function in the developing brain, we generated several Vps35 cKO mouse lines, named as Vps35 ${ }^{\text {GFAP-Cre }}$, Vps35 ${ }^{\text {Emx1-Cre }}$, and Vps35 $5^{\text {NeuroD6-Cre }}$, by crossing the floxed Vps35 allele $\left(\mathrm{Vps}^{\mathrm{f}} 5^{\mathrm{f} / \mathrm{f}}\right)$ with hGFAP-Cre, Emx1-Cre, and NeuroD6Cre mice, respectively. Note that the hGFAP-Cre expresses Cre in astrocytes, RGCs, NSCs, and their progenies beginning at E13.5 (Zhuo et al., 2001). The Emx1-Cre expresses Cre in progenitors and postmitotic neurons of telencephalic cortical divisions, including RGCs, Cajal-Retzius cells, glutamatergic neurons, and astrocytes, beginning at E10.5 (Gorski et al., 2002). The Neurod6-Cre expresses
Cre selectively in pyramidal neurons, granule and mossy cells of dentate gyrus in neocortex and hippocampus, starting at E11.5 (Goebbels et al., 2006). Vps35 expression was abolished in $\mathrm{Cre}^{+}$ cells in these mutant mouse lines (Tang et al., 2020; data not shown); and all of these Vps35 cKO mice appeared to be smaller in body size with reduced body weight, and underwent early death around ages of P21-P28 (data not shown).

We then examined phenotypes of these Vps35 cKO mice at $\mathrm{P} 1, \mathrm{P} 7$, and P14. Initial viewing overall brain structures of P14 mice showed smaller brain in size in $\mathrm{Vps} 35^{\text {Neurod6-Cre }}$, but not in $\mathrm{Vps} 35^{\text {GFAP-Cre }}$ and Vps35 $5^{\mathrm{EMX1-Cre}}$, as compared with their littermate control mice (Vps35 $5^{\mathrm{f} / \mathrm{f}}$; Fig. $1 \mathrm{~A}$ ). Interestingly, the lateral hind brains in $\mathrm{Vps} 35^{\mathrm{GFAP}-\mathrm{Cre}}$ and $\mathrm{Vps} 35^{\mathrm{EMX1}-\mathrm{Cre}}$, but not Vps $35^{\text {NeuroD6-Cre }}$, mice appeared to be transparent (Fig. 1A), likely due to the accumulation of "water" in their ventricles, implicating a hydrocephalus deficit. Further Nissl staining analysis of their brain sections at ages of P1, P7, and P14 showed cortical atrophy in all three mutant mouse lines at ages of $>$ P7, but not P1 (Tang et al., 2020; data not shown). But, the enlarged LVs, a morphologic feature of hydrocephalus, were noted in Vps $35^{\text {GFAP-Cre }}$ and Vps $35^{\text {Emx1-Cre }}$, but not Vps $35^{\text {NeuroD6-Cre }}$, mice, at ages of $\mathrm{P} 7$ or older (Fig. $1 B-F$ ). These results suggest a 
A

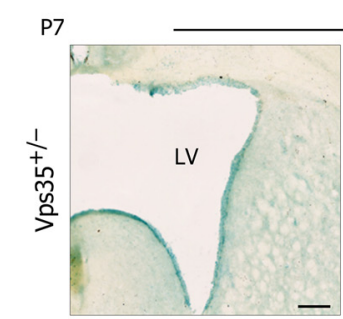

C

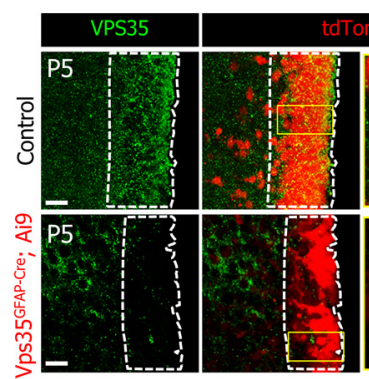

E

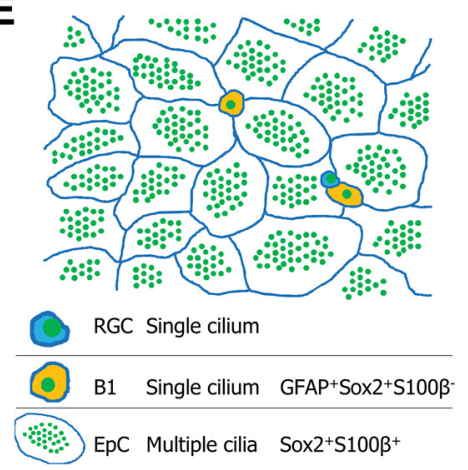

B

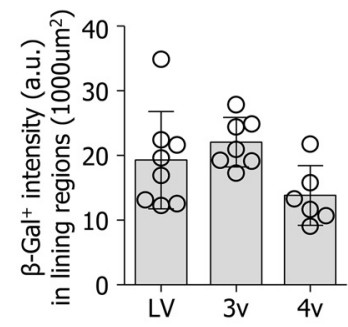

D
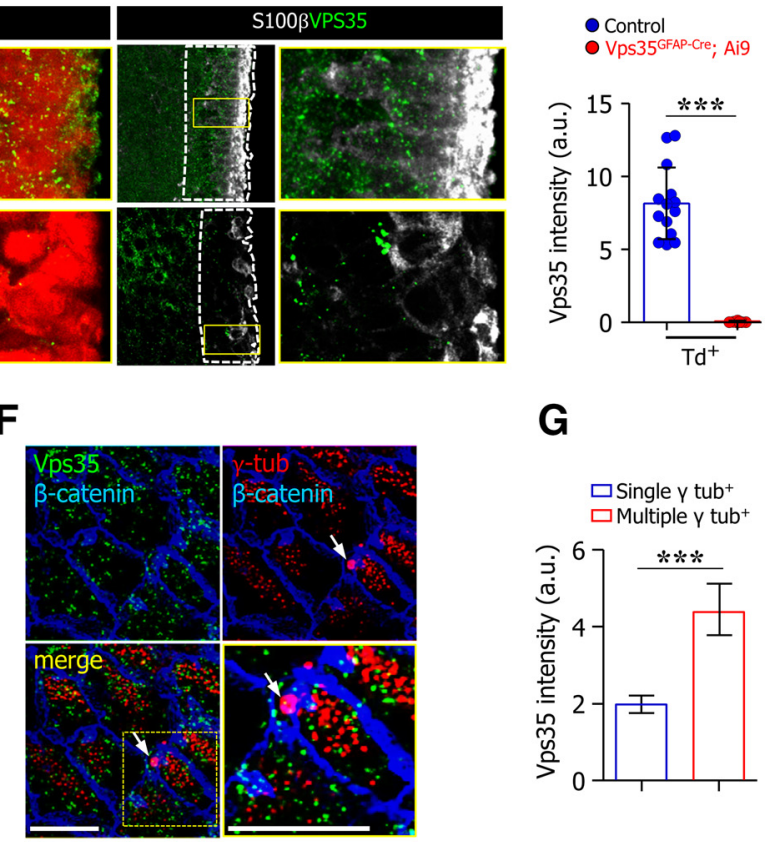

G

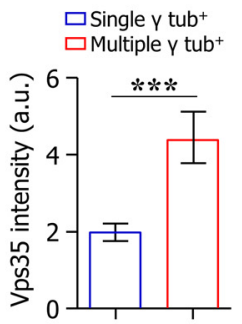

Figure 3. Vps35 expression in EpCs. $\boldsymbol{A}, \boldsymbol{B}$, LacZ activity in P7 Vps35+ / - mouse brain slices. $\boldsymbol{A}$, Representative images. LV, 3V, and $4 \mathrm{~V}$ are indicated. Scale bar, $200 \mu \mathrm{m}$. $\boldsymbol{B}$, Quantification of data in $\boldsymbol{A}$, the LacZ activity. C, Representative images of immunofluorescence signals for endogenous Vps35 (green), td (red), and S100 $\beta$ (white) in P5 control (GFAP-Cre; Ai9) and Vps35 GAP-Cre; Ai9 LVlining regions. Scale bars, $20 \mu \mathrm{m}$. D, Quantification of Vps35 immunofluorescence intensity in $\mathrm{td}^{+}$cells in control and Vps35 ${ }^{\text {GFAP-Cre; }}$; Ai9 mice. Data shown are mean \pm SEM $(n=3)$; *** $p<$ 0.001, Student's $t$ test. $\boldsymbol{E}$, Illustration of major cell types in LV medial wall facing ventricular lumen. RGC (RGCS with single cilium), B1 cells (also called NSCS, with single cilium), and EpCs (EpCs with multiple cilia) are indicated. Green dots represent basal body of cilium. $\boldsymbol{F}$, Representative images of whole-mount immunostaining analysis of VPS35 (green), $\gamma$-tub (red), and $\beta$-catenin (blue) in P7 LV medial wall. Note that the $\gamma$-tub marks basal body of cilium, and $\beta$-catenin labels cell-cell junctions. Arrow points to the cell with single cilium (RGC or B1 cell). Scale bars, $10 \mu \mathrm{m}$. $\mathbf{G}$, Quantification of VPS35 immunofluorescence intensity in multicilium and single-cilium-containing cells. VPS35 immunofluorescent signal distributed in cell-cell junctions were excluded. Data shown are mean \pm SEM from three experiments; ${ }^{* *} p<0.001$, Student's $t$ test.

hydrocephalus-like deficit in Vps $35^{\text {GFAP-Cre }}$ and Vps $35^{\text {Emx1-Cre }}$, but not Vps35 $5^{\text {NeuroD6-Cre }}$, mice.

We further examined the enlarged LV and other morphologic phenotypes in different brain regions of the mutant (Vps35 GFAP-Cre and $\left.\mathrm{Vps} 35^{\text {Emx1-Cre }}\right)$ mice. In Vps35 $5^{\text {GFAP-Cre }}$ mice $(\geq \mathrm{P} 7)$, obviously enlarged LVs in both anterior and posterior brains were observed (Fig. 1D-F). Additionally, the left and right hemispheric LVs were fused into one large lumen at the anterior brain (Fig. $1 D$, top row); the posterior cortex was much thinner (Fig. $1 D$, bottom row); and the hippocampal formation was impaired (Fig. 1D). In Vps35 ${ }^{\text {Emx1-Cre }}$ mice (at and after P7), similar but less severe phenotypes as those in $\mathrm{Vps} 35^{\mathrm{GFAP}-\mathrm{Cre}}$ mice were detected (Fig. $1 D-F$ ). The phenotypes, including enlarged LVs, thinner cortex, and impaired hippocampal formation, were obvious in the posterior, but not anterior brains, in Vps35 ${ }^{\text {Emx1-Cre }}$ mice (Fig. $1 D-F$ ). Quantification of the index of LV enlargement (total LV area in each genotype over total LV area in control mice) showed most severe phenotype in Vps35 $5^{\text {GFAP-Cre }}$ mice as compared with Vps35 ${ }^{\text {Emx1-Cre }}$ mice, which had $>30$-fold increase in LV areas at P14, whereas Vps35 $5^{\text {Emx1-Cre }}$ mice had $\sim 10$-fold increase (Fig. $1 G$ ). Note that in both mutant brains, the third (third) and fourth (fourth) ventricles, as well as the Aq appeared to be unaffected. (data not shown). These results suggest a selective deficit in LVs in both Vps35 $5^{\text {GFAP-Cre }}$ and $\mathrm{Vps} 35^{\text {Emx1-Cre }}$ mice.

As the enlarged LV phenotype was less obvious in fractions of Vps $35^{\text {Emx1-Cre }}$ mice, we further examined their potential hydrocephalic deficit by use of magnetic resonance imaging (MRI), a more sensitive and non-invasive imaging method to examine LV lumen and structures in live animals. Vps $35^{\text {Emx1-Cre }}$ mice and their littermate controls $\left(\mathrm{Vps} 35^{\mathrm{f} / \mathrm{f}}\right)$ at age of P14. Indeed, the light intensity (white) in LVs were increased and enlarged at the posterior brains of $\mathrm{Vps} 35^{\mathrm{Emx1-Cre}}$ mice, as compared with their control mice (Fig. 1H,I). These observations provide additional evidence for a hydrocephalic deficit in $\mathrm{Vps} 35^{\mathrm{Emx1-Cre}}$ mice.

\section{Active Cre expression in LV lining cells in GFAP-Cre and Emx1-Cre, but not Neurod6-Cre, mice}

The hydrocephalic deficits were detectable in Vps $35^{\text {GFAP-Cre }}$ and $\mathrm{Vps} 35^{\text {Emx1-Cre }}$, but not $\mathrm{Vps} 35^{\text {NeuroD6-Cre }}$, mice, raising a question 
A

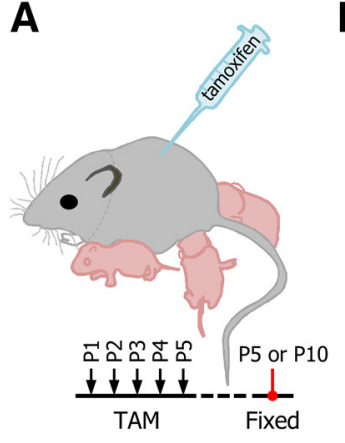

B

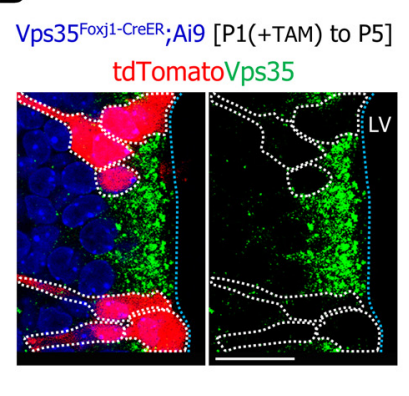

C

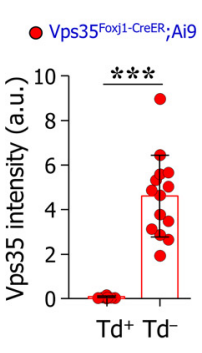

D

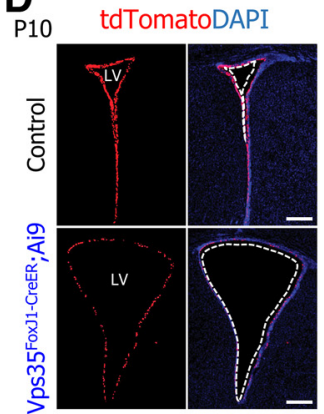

E

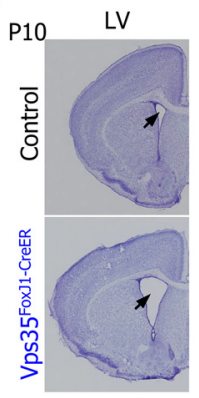

$\mathbf{F}$

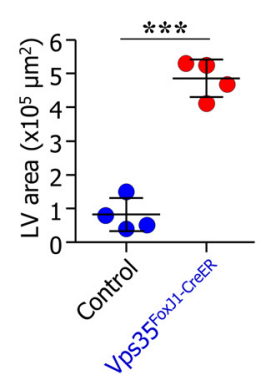

G

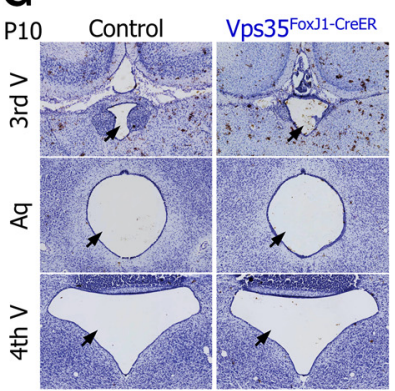

H

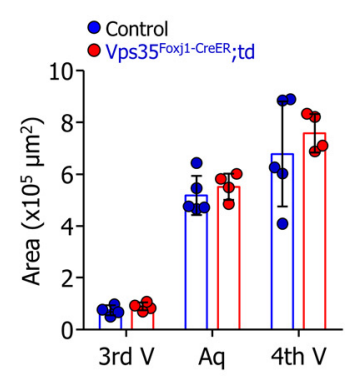

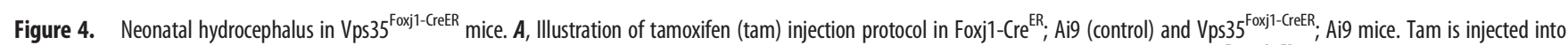
pups for five times starting at P1. B, Representative images of immunofluorescence signals for endogenous Vps35 (green) and td (red) in P5 Vps35 ${ }^{\text {Foxji-creeR; }}$; Ai9 LV-lining region. Scale bars, $20 \mu \mathrm{m}$. C, Quantification of data in $\boldsymbol{B}$, VPS35 immunofluorescence intensity in $\operatorname{td}^{+}$and $\operatorname{td}^{-}$cells. Data shown are mean $\pm \mathrm{SEM}(\mathrm{n}=4) ;{ }^{* * *} p<0.001$, Student's $t$ test. $\boldsymbol{D}$, The td images in P10 control and Vps35 $5^{\text {Foxj-CreER; }}$; Ai9 mice. LVs are indicated. Scale bar, $100 \mu \mathrm{m}$. E, Nissl staining of P10 mouse brains of control and Vps35 $5^{\text {Foxj1-creeR }}$ mice. Arrows indicate LV lumen. Scale bar, $500 \mu \mathrm{m} . \boldsymbol{F}$, Quantification of LV area of control and Vps35 $5^{\text {Foxi-CreER }}$ mice. Data shown are mean \pm SEM from four mice; ${ }^{* * *} p<0.001$, Student's $t$ test. G, Nissl staining of P10 mouse $3 V$, Aq, and $4 \mathrm{~V}$ of control and Vps35 $5^{\text {Foxji-CreER }}$ mice. Ventricle lumens are indicated by arrows. Scale bar, $100 \mu \mathrm{m}$. $\boldsymbol{H}$, Quantification of 3V, Aq, and $4 \mathrm{~V}$ area of control and Vps35 $5^{\mathrm{Foxj} 1-\text {-CreER }}$ mice. Data shown are mean \pm SEM from five control mice and four Vps $35^{\text {Foxj1-CreER }}$ mice. Student's $t$ test.

of why Vps35 KO in GFAP-Cre ${ }^{+}$or EMX1-Cre ${ }^{+}$cells, but not Neurod6-Cre ${ }^{+}$cells, causes LV enlargement. To address this question, we tested whether this difference was due to different Cre expression in cells surrounding LVs. To this end, the hGFAP-Cre, Emx1-Cre, and Neurod6-Cre mice were crossed with Ai9 mice, which serves as Cre activity reporter via tdTomato (td) expression that is controlled by Cre recombinase (Madisen et al., 2010). Imaging td fluorescence in brain sections of these mice at P7 showed $\mathrm{td}^{+}$signals in cortex (Ctx), corpus callosum (CC), and striatum (Str) in all three mouse lines (Fig. $2 A)$. However, the $\mathrm{td}^{+}$signals were only detected in cells surrounding LVs in hGFAP-Cre; Ai9 and Emx1-Cre; Ai9, but not NeuroD6-Cre; Ai9, mice (Fig. 2A,B). Further examining td expression pattern in the lining of LV showed positive signals along three walls of LVs with highest expression in the medial wall in GFAP-Cre; Ai9 mice (Fig. 2B). The Emx1-Cre;Ai9 mice exhibited a selective expression pattern, with td signals in the dorsal wall and part of medial wall, but undetectable in the lateral wall and ventral part of medial wall (Fig. 2B), in line with a previous report (Gorski et al., 2002). In addition, Emx1-Cre, but not GFAP-Cre, was expressed in choroid plexus (Fig. 2C). These results suggest that the active Cre expression in LV lining cells may contribute to the hydrocephalic deficits in $\mathrm{Vps} 35^{\text {GFAP-Cre }}$ and $\mathrm{Vps} 35^{\text {Emx1-Cre }}$, but not Vps35 $5^{\text {Neurod6-Cre }}$, mice.

\section{Vps35 expression in EpCs}

EpC is a major type of cells lining the LV, with cilia extending into the LV lumen, and dysfunctional EpCs result in hydrocephalus (Spassky et al., 2005; Mirzadeh et al., 2008). We thus asked whether ependymal Vps35 is necessary for prevention of hydrocephalus. To this end, we first asked whether Vps35 is expressed in ependymal regions of Vps35+/- mice, which contain Vps35-promoter driven LacZ reporter (Wen et al., 2011). Indeed, the activity of $\beta$-gal was positive in lining regions of $\mathrm{LV}$ as well as other ventricles (e.g., $3 \mathrm{~V}$ and $4 \mathrm{~V}$ ) at $\mathrm{P} 7$ mouse brains (Fig. $3 A, B$ )

Second, we examined VPS35 expression in control (GFAPCre; Ai9) and Vps35 ${ }^{\text {GFAP-Cre }}$; Ai9 LV-brain sections (at P5) by coimmunostaining analysis using antibodies against td and VPS35. The immunosignal of VPS35 was detected in $\mathrm{td}^{+} \mathrm{S} 100 \beta^{-}$ cells (likely to be RGCs and EpC precursors) and $\mathrm{td}^{+} \mathrm{S} 100 \beta^{+}$ cells (likely to be EpCs) in control mice (Fig. 3C,D). These immunosignals of VPS35 were undetectable in $\mathrm{td}^{+}$cells in $\mathrm{Vps} 35^{\mathrm{GFAP}-\mathrm{Cre}}$; Ai9 mice (Fig. $3 C, D$ ); but the $\mathrm{td} / \mathrm{Cre}^{-}$cells contained VPS35 ${ }^{+}$signal (Fig. 3C). These results not only demonstrate VPS35's expression in EpCs and their precursors, but also verify the specificity of Vps35 antibody.

Third, we examined VPS35's expression in EpCs and other types of cells in the ependymal region by whole-mount coimmunostaining analysis. As illustrated in Figure 3E, EpCs and type B1 cells are the two major types of cells in LV lining layer facing the ventricular lumen. Both EpCs and B1 cells are derived from RGCs (Spassky et al., 2005; Jacquet et al., 2009; Fuentealba et al., 2015). The B1 cells and RGCs have one primary cilium, while EpCs contain multicilia, and the base of these cilia can be labeled by $\gamma$-tub (Mirzadeh et al., 2008). Whole-mount coimmunostaining analysis using antibodies against VPS35, $\gamma$-tub, and $\beta$-catenin (to mark cell boundaries) showed abundant VPS35 puncta in $\gamma$-tub marked multicilia cells (likely to be EpCs), whereas fewer VPS35 puncta in the singlecilium cells (likely to be RGC/B1 cells; Fig. $3 E-G$ ). These results provide additional evidence for Vps35's expression in EpCs. 
Similar LV hydrocephalus in ependymal Vps35 cKO mice, Vps35 ${ }^{\text {Foxj1-CreER }}$

We next determined whether selectively KO Vps35 in EpCs was sufficient to cause hydrocephalus. To this end, we generated ependymal-specific Vps35 KO mice, Vps $35^{\text {Foxj1-CreER }}$, by crossing $\mathrm{Vps}_{35^{\mathrm{f} / \mathrm{f}}}$ with Foxj1-Cre ${ }^{\mathrm{ER}}$ mice. The Cre expression in Foxj1$\mathrm{Cre}^{\mathrm{ER}}$ mouse line, under the control of forkhead transcription factor J1 (Foxj1) promoter, is selectively turned on in ependymal progenitors and terminally differentiated EpCs on tamoxifen treatment (Jacquet et al., 2009; Muthusamy et al., 2014). Upon tamoxifen (TAM) treatment (P1-P5 pups) of Vps35 $5^{\text {Foxj1-CreER; }}$ Ai9 mice (Fig. 4A), VPS35 expression was abolished in $\mathrm{td}^{+}$ EpCs, but remained high in $\mathrm{td}^{-}$cells in the LV-lining region (Fig. $4 B, C)$, demonstrating again VPS35's expression in EpCs and verifying the identity of $\mathrm{Vps} 35^{\text {Foxj1-CreER }}$;Ai9 mice. We then examined the LV structures in control (Foxj1-Cre; Ai9) and mutant (Vps35 ${ }^{\text {Foxj1-CreER }}$; Ai9) mice (at P10). Immunostaining analysis of $\mathrm{td}^{+}$signals showed selectively expression of $\mathrm{td}$ in LV-lining regions, which was reduced in the mutant $\mathrm{LV}$; but the mutant LVs were obviously enlarged (Fig. 4D), suggesting a hydrocephalus-like phenotype. Histologic examination of mutant pups $\left(\mathrm{Vps} 35^{\text {Foxj1-CreER }}\right)$ and their littermate controls showed little changes in cortex and hippocampal structures (Fig. 4E; data not shown). However, the LV area was also enlarged in $\mathrm{Vps} 35^{\text {Foxj1- }}$ CreER mice, as compared with that of control mice (Fig. 4E,F). The areas of $3 \mathrm{~V}, \mathrm{Aq}$, and $4 \mathrm{~V}$ in $\mathrm{Vps} 35^{\text {Foxj1-CreER }}$ mice were comparable to those of control mice (Fig. $4 G, H$ ). These results suggest that Vps35 KO in Foxj1-lineage EpCs is sufficient to cause LV enlargement, demonstrating the necessity of VPS35 in neonatal EpCs to prevent hydrocephalus.

To understand why LV, but not other ventricles, was selectively affected by Vps35 KO, we compared the Cre activity in different ventricles in Foxj1-Cre ${ }^{\mathrm{ER}}$; Ai9 pups (revealed by $\mathrm{td}^{+}$ signal). The Cre activity appeared to be more active in LV than that in other ventricles (3V and $4 \mathrm{~V}$; Fig. 5). These results suggest that the selective LV enlargement in the mutant mice may be due to LV-selective Cre-mediated depletion of the Vps35 gene. Alternatively, it is possible that the age (P1-P10) is a critical period for $\mathrm{LV}-\mathrm{EpC}$ maturation and function.

\section{Defective ciliogenesis of EpCs in both Vps35 ${ }^{\text {GFAP-Cre }}$ and Vps35 ${ }^{\text {Foxj1-CreER }}$ mice}

Dysfunctional ciliogenensis of EpCs is believed to be a key factor underlying communicating hydrocephalus (Fliegauf et al., 2007; Tissir et al., 2010; Ohata et al., 2014). We thus examined cilia morphology of EpCs in control and Vps35 cKO mice, $\mathrm{Vps} 35^{\text {GFAP-cre }}$ and Vps $35^{\text {Foxj1-CreER }}$, by coimmunostaining analysis of LV medial wall whole-mount preparations. The antibodies against ace-tub and $\gamma$-tub were used, as they can mark cilia and basal body of cilia, respectively (Mirzadeh et al., 2008; Delgehyr et al., 2015). The antibody against $\beta$-catenin was used to mark cell boundary. In control mice $\left(\mathrm{P} 10 \mathrm{Vps} 35^{\mathrm{f} / \mathrm{f}}\right)$, ace-tub ${ }^{+}$cilia in EpCs were well formed and nicely organized. However, in Vps $35^{\text {GFAP-Cre }}$ mice, the ace-tub ${ }^{+}$cilia density was largely reduced (Fig. 6A,B); and the intensity of ace-tub ${ }^{+}$multicilia per EpC was also decreased (Fig. 6C). In addition, the apical surface area of cells facing LV lumen (marked by $\beta$-catenin) was significantly altered in Vps35 ${ }^{\text {GFAP-Cre }}$ mice (Fig. $6 A, D$ ). As illustrated in Figure $6 A$, in addition to EpCs with multicilia, cells with single cilium are likely B1 cells or RGCs in lateral ventricular surface (Mirzadeh et al., 2008). We thus examined $\gamma$-tub marked multicilia and single-cilium-containing cells in control and $\mathrm{Vps} 35^{\text {GFAP-Cre }}$ mice. In control mice, most cells facing LV lumen
A

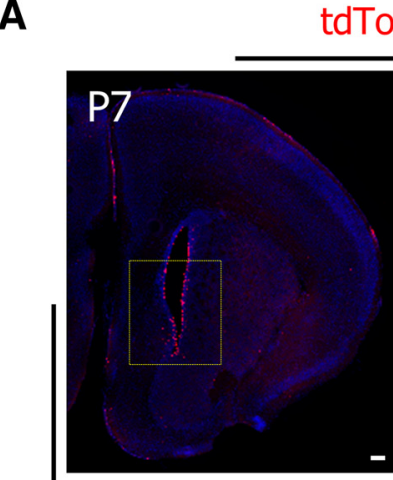

tdTomatoDAPI
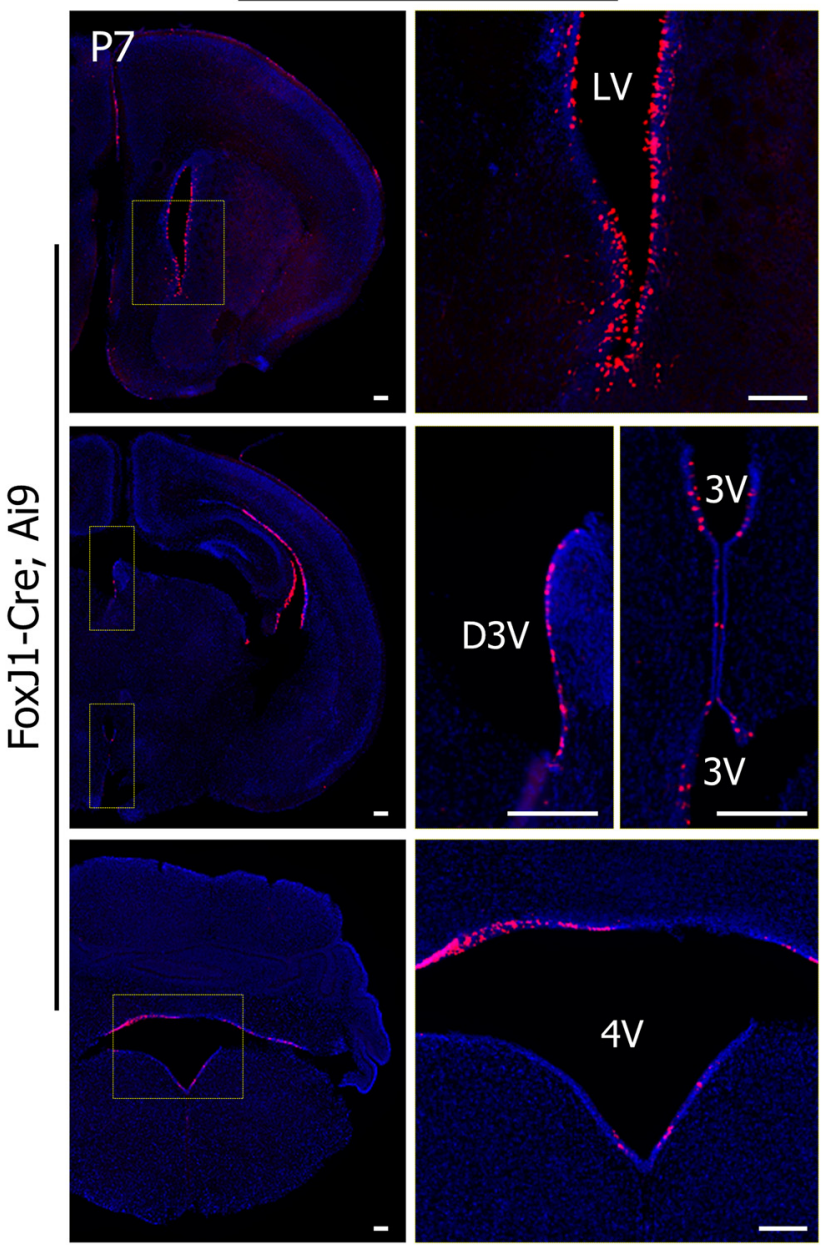

B

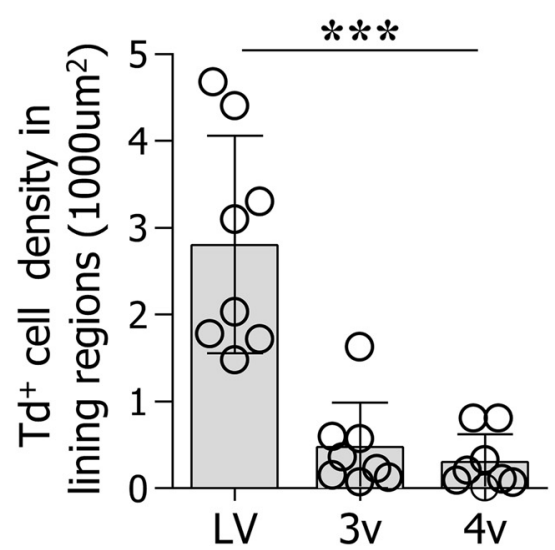

Figure 5. Cre recombinase activity in Foxj1-CreER mouse line. The Tam was injected into Foxj1-CreER; Ai9 pups for five times starting at P1. A, Representative $\mathrm{td}^{+}$fluorescence images of mouse brain at age of P7. Amplified images presented in right panels are from yellow boxes. Scale bars: $200 \mu \mathrm{m}$. $\boldsymbol{B}$, Quantification of data in $\boldsymbol{A}$, Cre activity, revealed by $\mathrm{td}^{+}$cell density, in indicated ventricles. Data shown are mean \pm SEM from seven brain sections of two mouse; ${ }^{* *} p<0.001$, one-way ANOVA with Bonferroni correction post hoc test.

contained multiple $\gamma$-tub dots (multiple cilium); few cells had single $\gamma$-tub dot (single cilium); and these multicilium or singlecilium-containing cells were all well organized and evenly distributed along the medial wall of LVs (Fig. 6D). However, in $\mathrm{Vps} 35^{\mathrm{GFAP}-\mathrm{Cre}}$ mice, the multicilia containing cells (likely to be 
A

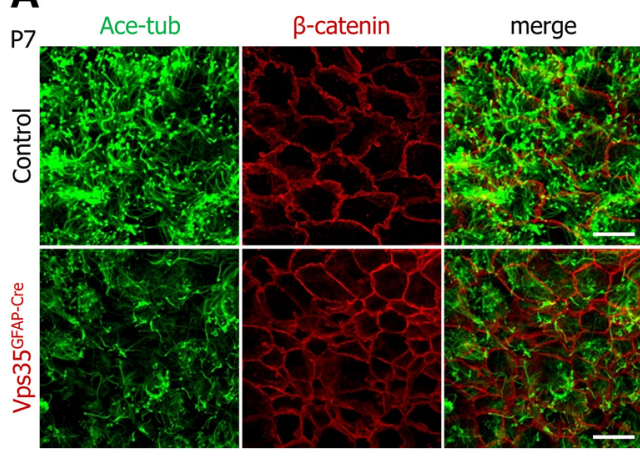

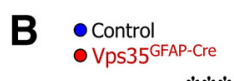

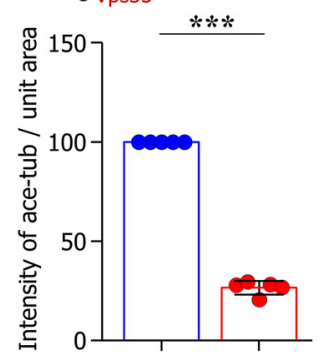

C

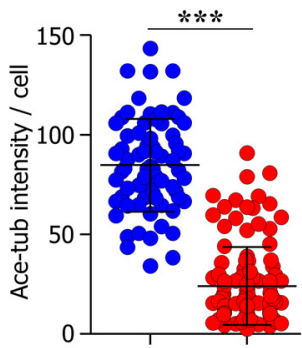

D

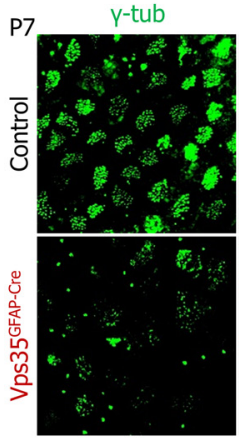

E

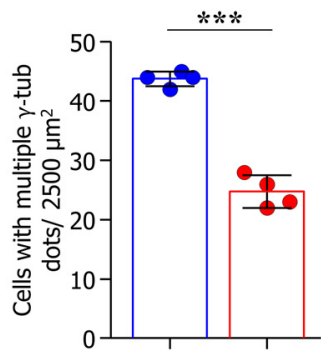

ß-catenin

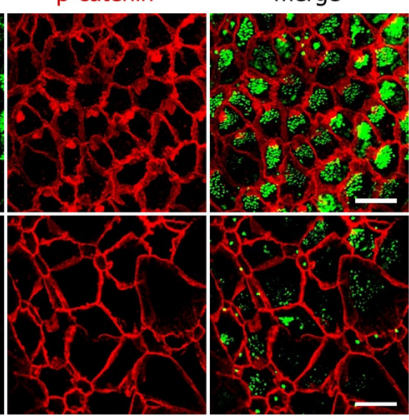

$\mathbf{F}$

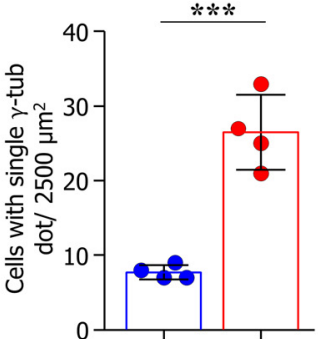

Figure 6. Disrupted cilium morphogenesis in Vps35 ${ }^{\text {GFAP-re }}$ mice. $A$, Representative images of whole-mount immunostaining analysis of ace-tub (green) and $\beta$-catenin (red) in LV medial walls of P7

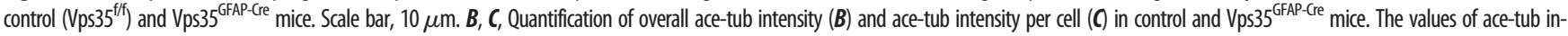
tensity in control mice are designated as 100. Data shown are mean \pm SEM from five mice in each group; ${ }^{* * *} p<0.001$, Student's $t$ test. $\boldsymbol{D}$, Representative images of whole-mount immunostaining analysis of $\gamma$-tub (green) and $\beta$-catenin (red) in LV medial walls of P7 control and Vps35 $5^{\text {GFAP-Cre }}$ mice. Scale bar, $10 \mu \mathrm{m}$. $\boldsymbol{E}, \boldsymbol{F}$, Quantification of data in $\boldsymbol{D}$. The numbers of multiple $\gamma$-tub-positive cells per area $(\boldsymbol{E})$ and the numbers of single $\gamma$-tub-positive cells per area $(\boldsymbol{F})$ are shown. Data shown are mean \pm SEM from four mice in each group; ${ }^{* * *} p<0.001$, Student's $t$ test.

A

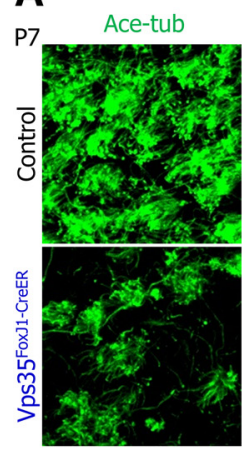

B $\bullet$ Control

- Vps35FoxJ1-CreER

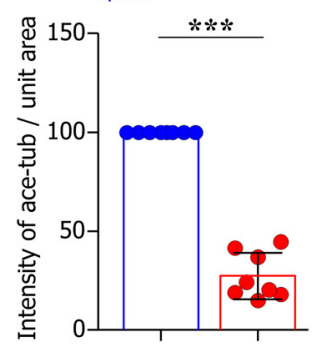

$\beta$-catenin

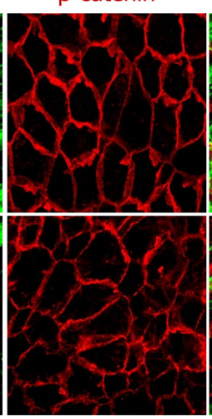

C

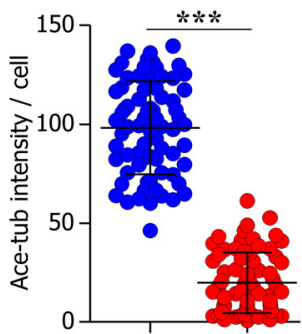

D
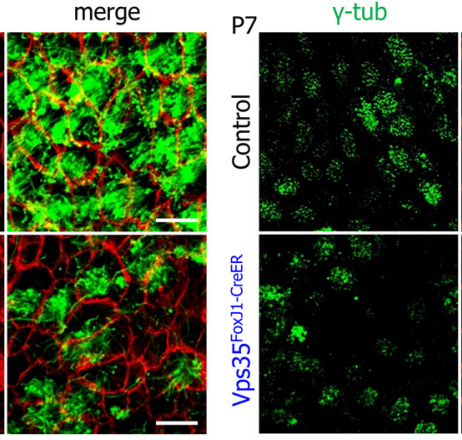

E

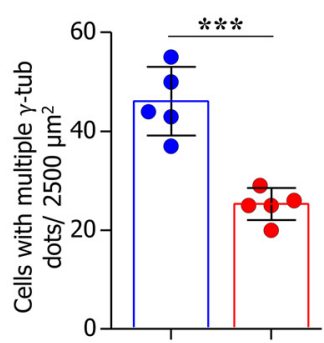

ß-catenin

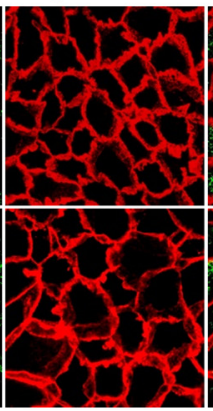

$\mathbf{F}$ merge
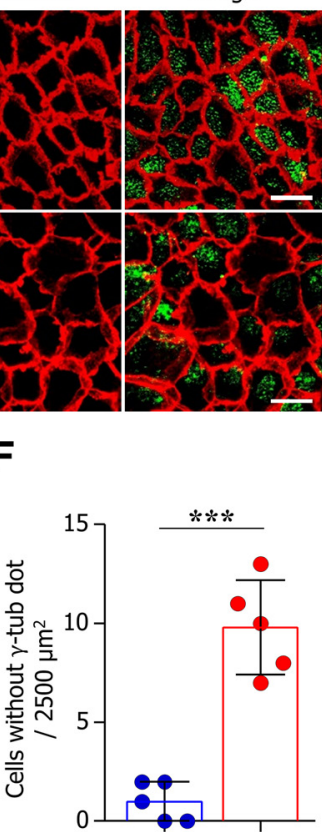

Figure 7. Impaired cilium formation in Vps $35^{\mathrm{Foxji}-\text {-reeR }}$ mice. $\boldsymbol{A}$, Representative images of whole-mount immunostaining analysis of ace-tub (green) and $\beta$-catenin (red) in LV medial walls

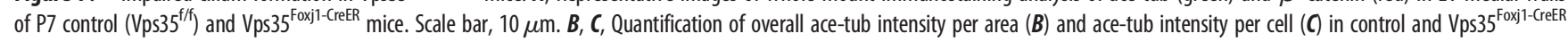
mice. The values of ace-tub intensity per area in control mice are designated as 100. Data shown are mean \pm SEM from five mice in each group; ${ }^{* * *} p<0.001$, Student's $t$ test. $\boldsymbol{D}$, Representative images of whole-mount immunostaining analysis of $\gamma$-tub (green) and $\beta$-catenin (red) in LV medial walls of P7 control (Vps35/f) and Vps35 ${ }^{\text {foxji-creeR }}$ mice. Scale bar, $10 \mu \mathrm{m}$. $\boldsymbol{E}, \boldsymbol{F}$, Quantification of data in $\boldsymbol{D}$. The numbers of multiple $\gamma$-tub-positive cells per area $(\boldsymbol{E})$ and the numbers of cells without $\gamma$-tub-positive signal per area $(\boldsymbol{F})$ are shown. Data shown are mean \pm SEM from five mice in each group; ${ }^{* * *} p<0.001$, Student's $t$ test. 
A
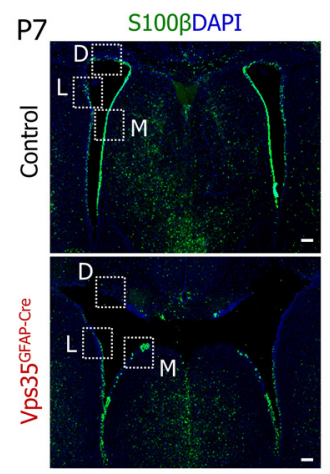

C

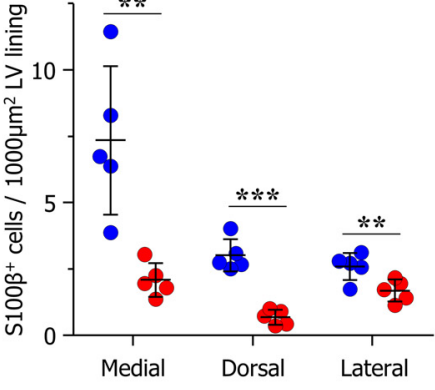

B
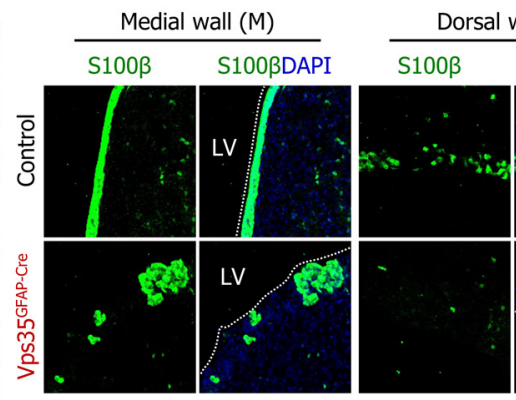

D

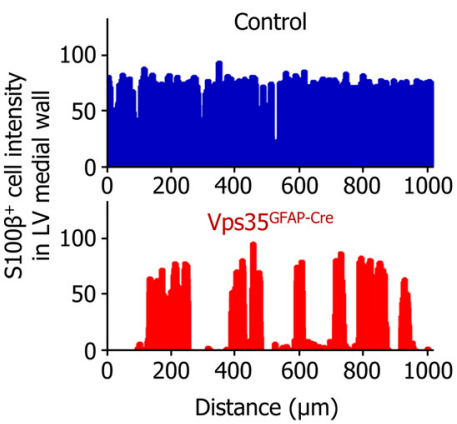

E

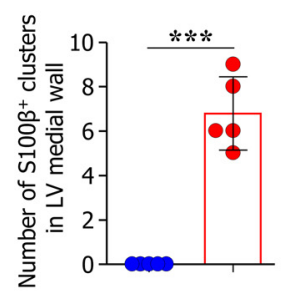

Figure 8. Disorganized and reduced S100 $\beta^{+}$EpCs in Vps35 $5^{\text {GFAP-Cre }}$ mice. $\boldsymbol{A}, \boldsymbol{B}$, Representative images showing the distribution of $\mathrm{S} 100 \beta^{+} \mathrm{EpCs}$ in $\mathrm{LV}$ regions of P7 control $\left(\mathrm{Vps} 35^{\mathrm{ff}}\right)$ and Vps $35^{\text {GFAP-Cre }}$ mice $(\boldsymbol{A})$. The regions in white dashed square are magnified and shown in $\boldsymbol{B}$. D: dorsal, L: lateral, M: medial. Scale bar, $100 \mu \mathrm{m}$. $\boldsymbol{C}$, Quantification of S100 $\beta^{+}$cells per indicated area in the entire lining region of each wall. Data shown are mean \pm SEM from five mice in each group; ${ }^{* *} p<0.01$, ${ }^{* * *} p<0.001$, Student's $t$ test. $\boldsymbol{D}$, Intensity of S100 $\beta^{+}$EpCs along $1000-\mu \mathrm{m} \mathrm{LV}$ medial wall of control and Vps35 ${ }^{\text {GFAP-Cre }}$ mice. $E$, Quantification of the number of $\mathrm{S} 100 \beta^{+} \mathrm{EpC}$ clusters in LV medial walls. Data shown are mean $\pm \mathrm{SEM}$ from five mice in each group; ${ }^{* * *} p<0.001$, Student's $t$ test.

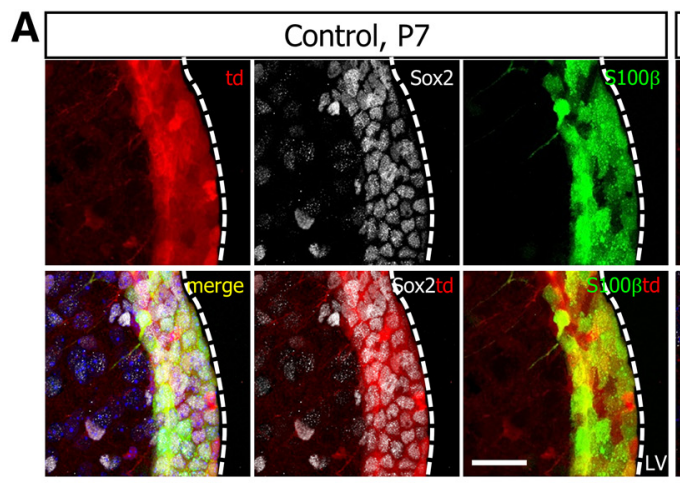

B : Control

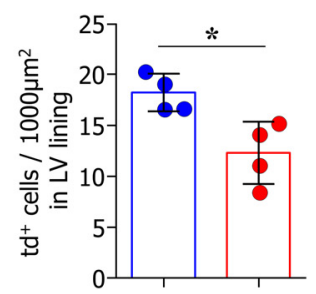

C

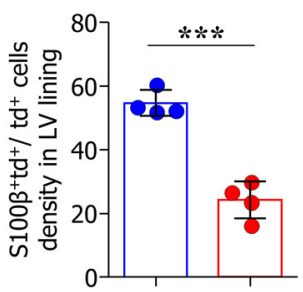

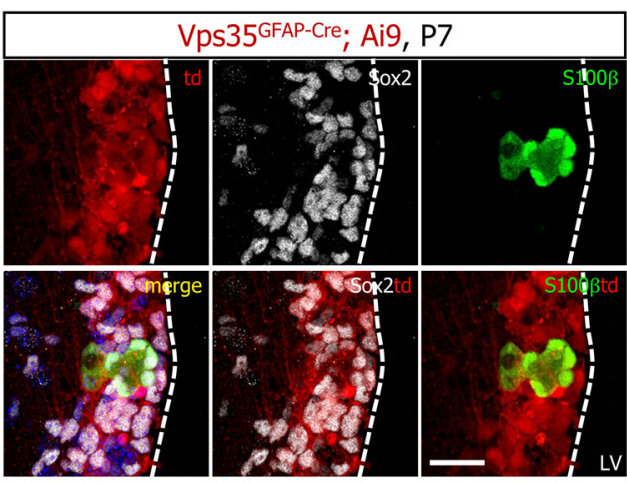

D

E

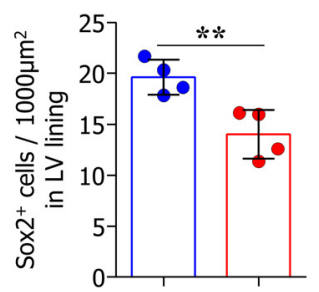

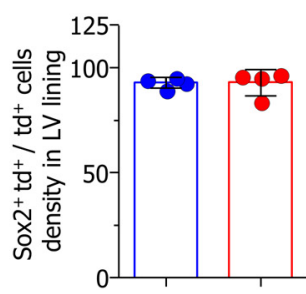

Figure 9. Decreased EpC differentiation in neonatal Vps35 $5^{\text {GFAP-Cre }}$ mice. $A$, Representative co-immunofluorescence images of $S 100 \beta$ (green), Sox2 (white), and td (red) in LV medial walls of P7 control (GFAP-Cre; Ai9) and Vps35 $5^{\text {GAAP-Cre }}$; Ai9 mouse brains. Scale bars, $20 \mu \mathrm{m}$. B, Quantification of $\mathrm{td}^{+}$cells per indicated area in LV-lining regions. C, Quantification of S100 $\beta^{+} \mathrm{td}^{+}$cells over $\mathrm{td}^{+}$cells in LV-lining regions. D, Quantification of Sox $2^{+}$cells per indicated area in LV-lining regions. E, Quantification of Sox2 ${ }^{+} \operatorname{td}^{+}$cells over $\mathrm{td}^{+}$cells in LV-lining regions. In $\boldsymbol{B}-\boldsymbol{E}$, data shown are mean \pm SEM from four mice in each group; ${ }^{*} p<0.05,{ }^{* *} p<0.01,{ }^{* * *} p<0.001$, Student's $t$ test. 
A P7

td

S100ß

Sox2

GFAP

merge
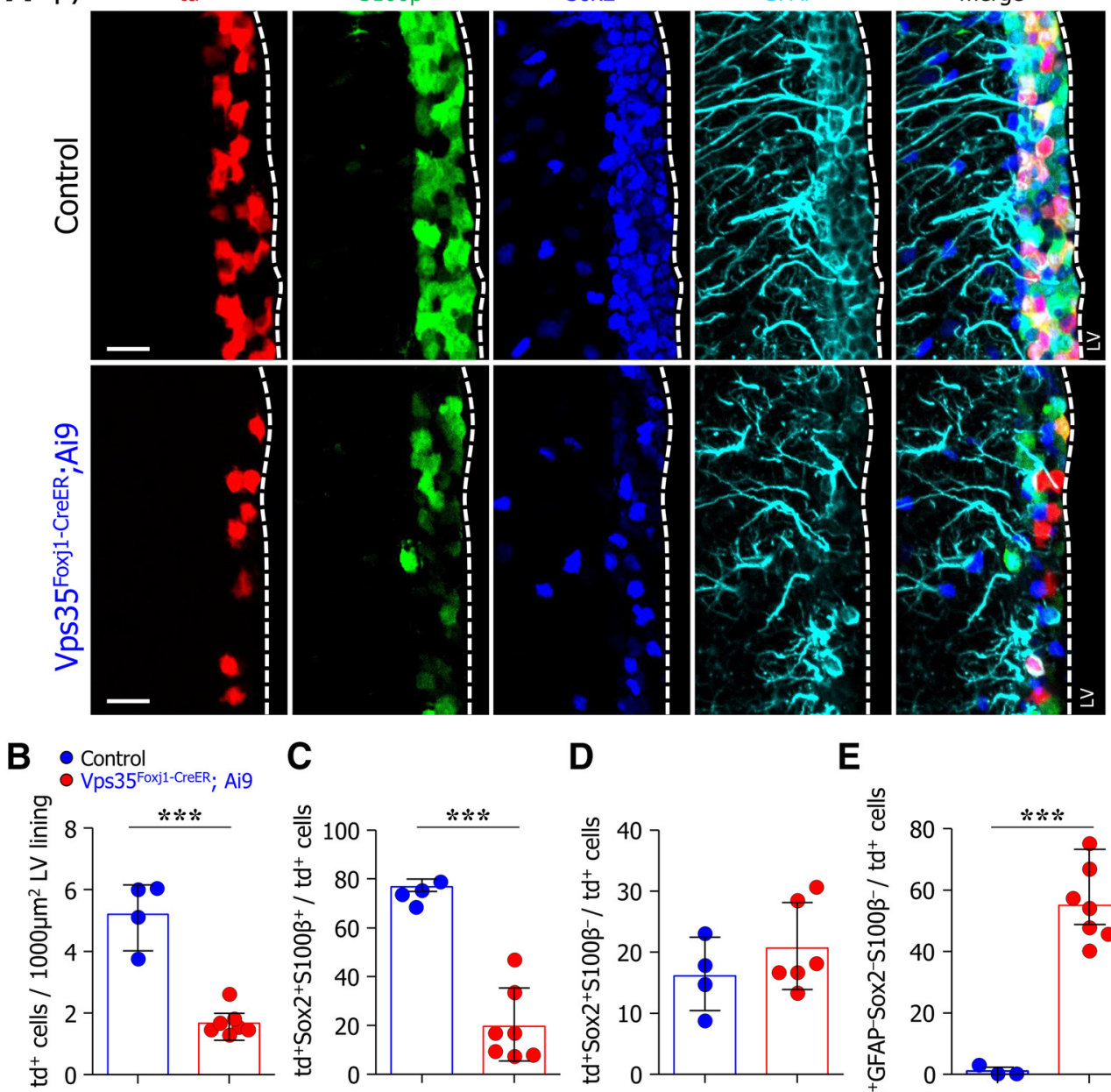

\section{c}

D

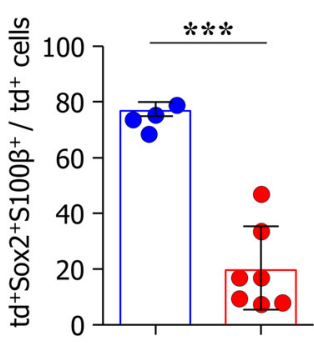

E

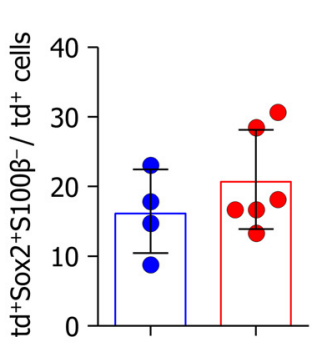

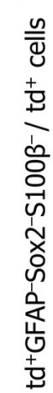

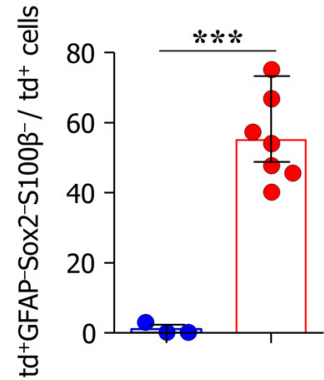

Figure 10. Decrease of EpCs, but increase of cells without known identify, in Vps35 $5^{\text {Foxj-CreER } L V-l i n i n g ~ r e g i o n s . ~} \boldsymbol{A}$, Representative co-immunofluorescence images of $S 100 \beta$ (green), GFAP (gray), Sox2 (blue), and td (red) in LV medial walls of P9 control (Foxj1-CreER; Ai9) and Vps35 $5^{\text {Foxj-CreeR } ; ~ A i 9 ~ m o u s e ~ b r a i n s . ~ S c a l e ~ b a r s, ~} 20 \mu \mathrm{m} . \boldsymbol{B}-\boldsymbol{E}$, Quantification of data in $\boldsymbol{A}$. td ${ }^{+}$cells per indicated area in LV-lining regions (B). S100 $\beta^{+}$Sox $2^{+} \mathrm{td}^{+}$cells over $\mathrm{td}^{+}$cells in LV-lining regions (C). S100 $\beta^{-} \mathrm{GFAP}^{+} \mathrm{Sox2}^{+} \mathrm{td}^{+}$over $\mathrm{td}^{+}$cells in $\mathrm{LV}$-lining regions (D). $\mathrm{td}{ }^{+}$S100 $\beta^{-}$ GFAP Sox $2^{-}$cells over $\mathrm{td}^{+}$cells in LV-lining regions $(\boldsymbol{E})$. Data shown are mean \pm SEM from four to six mice in each group; ${ }^{* * *} p<0.001$, Student's $t$ test.

EpCs) were markedly reduced (Fig. 6D-F), while cells with single $\gamma$-tub dot (non-EpCs, likely to be B1 cells or RGCs) were dramatically increased (Fig. 6D-F). These results suggest that Vps35 in GFAP-Cre ${ }^{+}$cells are likely to promote EpC genesis, ciliogenesis, and distribution, and thus, regulating LV surface organization and function.

We then examined cilia morphology in $\mathrm{Vps} 35^{\text {Foxj1-CreER }}$ and their littermate control $\left(\mathrm{Vps} 35^{\mathrm{f} / \mathrm{f}}\right)$ mice. The pups were exposed to tamoxifen as described in Figure $4 A$ or in Materials and Methods. P10 whole-mount preparations of mouse LV medial walls were subjected to coimmunostaining analysis. Similar cilia deficits in $\mathrm{Vps} 35^{\text {Foxj1-CreER }}$ mice were observed as those inVps35 $5^{\text {GFAP-Cre }}$ mice, which include reductions in ace-tub ${ }^{+}$ multicilia cells (likely to be EpCs; Fig. $7 A, B$ ) and in ace-tub ${ }^{+}$cilia intensity per EpC (Fig. 7A,C). However, compared with the control mice, the apical surface area of cells was relatively normal in Vps35 ${ }^{\text {Foxj1-CreER }}$ mice (Fig. $7 A, D$ ). In viewing $\gamma$-tub ${ }^{+}$basal bodies of cilia, the cells with multiple $\gamma$-tub ${ }^{+}$dots were dramatically dropped in $\mathrm{Vps} 35^{\text {Foxj1-CreER }}$ mice compared with that of control mice (Fig. $7 D, E$ ). Interestingly, many cells without $\gamma$-tub ${ }^{+}$signal were detected in Vps35 ${ }^{\text {Foxj1-CreER }}$, but not control, mice (Fig. $7 D, F$ ), indicating that these cells lost cilium. These $\gamma$-tub ${ }^{-}$cells had variable cellular sizes, some were comparable to EpCs, and some were small with a comparable size to single-cilium-containing cells (Fig. $7 D$ ), yet their cell identities remained unknown.

Taken together, these results demonstrate not only a defective ciliogenesis, but also a reduction in EpCs in both Vps35 GFAP-Cre and $\mathrm{Vps} 35^{\text {Foxj1-CreER }}$ mice.

\section{Reduced EpC differentiation in both Vps $35^{\text {GFAP-Cre }}$ and} Vps35 ${ }^{\text {Foxj1-CreER }}$ mice

The reduced multiciliated cells and the increased single $\gamma$-tub ${ }^{+}$ dot containing cells in $\mathrm{Vps} 35^{\mathrm{GFAP}-\mathrm{Cre}}$ mice or $\gamma$-tub ${ }^{-}$cells in $\mathrm{Vps} 35^{\text {Foxj1-CreER }}$ mice led us to speculate an alteration in EpC differentiation from RGCs in both mutants. To test this hypothesis, we first examined EpC density in control and Vps35 ${ }^{\text {GFAP-cre }}$ LVs at P7 using an antibody against $\mathrm{S} 100 \beta$, a calcium binding protein that marks differentiated EpCs (Ohata et al., 2014; Shimada et al., 2017). As shown in Figure $8 A-C, \mathrm{~S} 100 \beta^{+}$cells were distributed along the walls of LVs, with highest density in the medial wall of the control mice. However, in Vps35 GFAP-Cre mice, the $\mathrm{S} 100 \beta^{+}$cells were marked reduced in all three walls (dorsal, ventral, and medial walls) of LVs, but more severe in the 
A

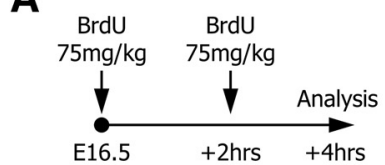

C Control

- Vps35 $5_{\text {GAP-Cre; }}$ Ai9
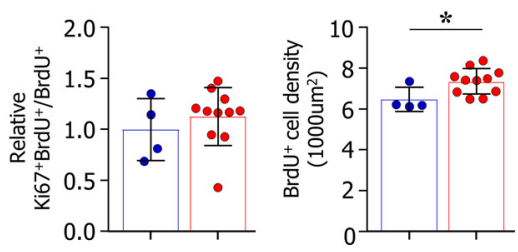

E

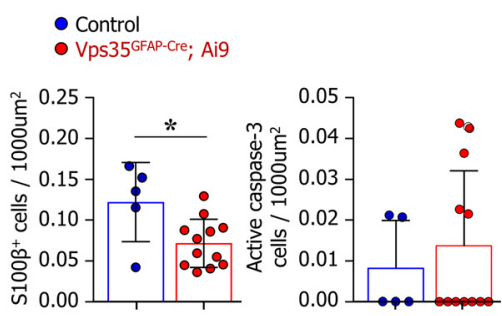

B

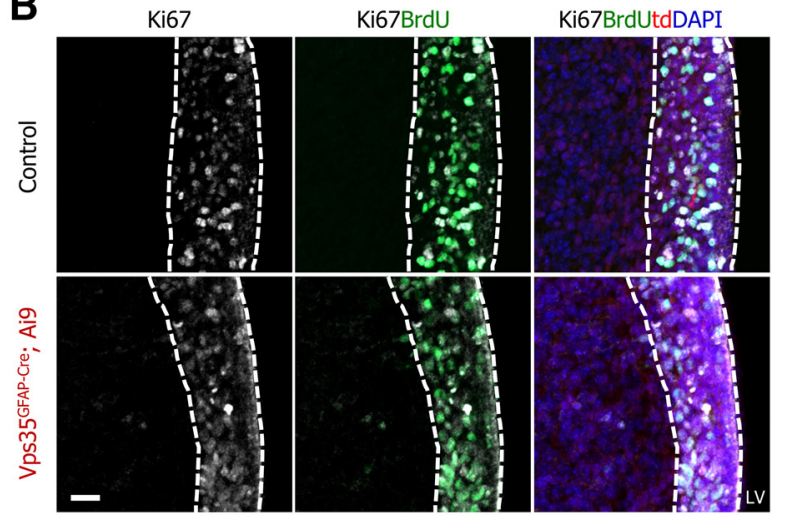

D Active Caspase-3 $\mathrm{S} 100 \beta$

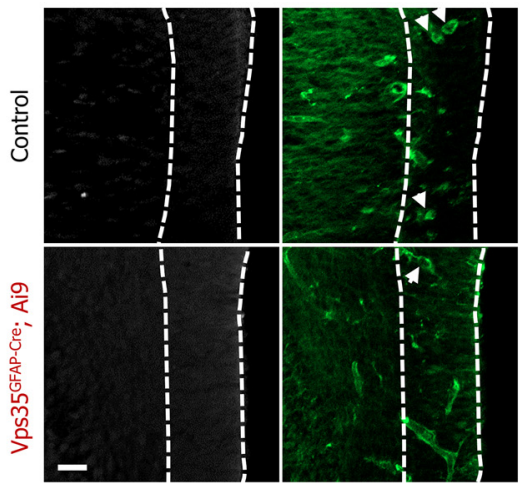

Active Caspase-3 S100ßtdDAPI

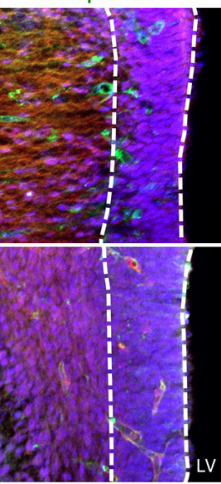

Figure 11. Comparable cell proliferation and cell death in E16.5 Vps35 ${ }^{G F A P-C r e}$ LV-lining regions to those of controls. A, Experimental procedure of BrdU incorporation into pregnant mothers. $\boldsymbol{B}$, Costaining of Ki67 and BrdU in control (GFAP-Cre; Ai9) and Vps35 $5^{\text {GFAP-Cre, }}$; Aig brain sections-LV-lining regions at E16.5. Scale bar, $20 \mu \mathrm{m}$. C, Quantifications of Ki67 ${ }^{+}$BrdU $^{+}$over BrdU ${ }^{+}$cells (left panel), and BrdU ${ }^{+}$cells per indicated area (right panel). Data shown are mean \pm SEM; ${ }^{*} p<0.05$, Student's $t$ test. $\boldsymbol{D}$, Costaining of activated Caspase 3, S100 $\beta$, and td in control (GFAP-Cre; Ai9) and Vps35 ${ }^{\text {GFAP-Cre; }}$; Ai9 LV-lining regions at E16.5. Scale bar, $20 \mu \mathrm{m}$. E, Quantifications of S100 $\beta^{+}$cells per indicated area (left panel), and activated Caspase $3^{+}$cells per indicated area (right panel). Data shown are mean \pm SEM; ${ }^{*} p<0.05$, Student's $t$ test.

medial wall (Fig. $8 A-C$ ). In addition, $\mathrm{S} 100 \beta^{+}$cells distribution pattern was altered in the mutant mice, exhibiting clustered $\mathrm{S} 100 \beta^{+}$ cells in some area, but missing in other areas (Fig. $8 B, D, E$ ). These results confirmed the reduction of EpCs in Vps35 ${ }^{\text {GFAP-Cre }}$ LVs, in line with the view for Vps35 in GFAP-Cre ${ }^{+}$lineage cells to be critical for EpC differentiation and distribution.

Second, we tested this hypothesis by generation and characterization of $\mathrm{Vps} 35^{\text {GFAP-Cre }}$; Ai9 mice by coimmunostaining analysis using various antibodies. As compared with the control mice (GFAP-Cre; Ai9), the density of $\mathrm{td}^{+}$cells in the medial wall of LVs was reduced (Fig. $9 A, B$ ) and the ratio of $\mathrm{td}^{+} \mathrm{S} 100 \beta^{+}$ (double positive) cells over total $\mathrm{td}^{+}$cells was decreased in Vps35 ${ }^{\text {GFAP-Cre }}$; Ai9 mice (Fig. 9A,C), supporting the view for a reduced EpC differentiation. In addition, the density of Sox $2^{+}$(a marker for stem cells) cells was lower in the mutant than those of control mice (Fig. 9A,D), and the Sox $2^{+}$cell distribution was also altered (Fig. 9A). However, the ratio of $\mathrm{td}^{+}$Sox $2^{+}$(double positive) cells over total $\mathrm{td}^{+}$cells appeared to be comparable between control and Vps35 ${ }^{\text {GFAP-Cre }}$ mice (Fig. 9A,E), suggesting Sox ${ }^{+}$cell reduction was proportional to $\mathrm{td}^{+}$cell reduction in Vps35 ${ }^{\text {GFAP-Cre }}$ mice. These results provide additional support for an important role of $\mathrm{Vps} 35$ in promoting EpC genesis/differentiation from RGCs.

Third, we examined whether Vps35 in Foxj1 derived EpC progenitors plays a similar role in postnatal EpC genesis/differentiation. Coimmunostaining analysis using these marker antibodies in Vps35 ${ }^{\text {Foxj1-Cre }}$; Ai9 and control (Foxj1-CreER; Ai9) mice showed marked reductions in not only $\mathrm{td}^{+}$cells, but also S100 $\beta^{+}$Sox $2^{+} \mathrm{td}^{+}$cells (Fig. $10 A-C$ ), supporting the view for a decreased EpC genesis/differentiation. However, the $\mathrm{GFAP}^{+}$ Sox $2^{+}$S $100 \beta^{-}$cells appeared to be comparable between control and $\mathrm{Vps} 35^{\text {Foxj1-Cre }}$ mice (Fig. $10 A, D$ ), similar result as that in $\mathrm{Vps} 35^{\mathrm{GFAP}-\mathrm{Cre}}$ mice. Interestingly, many $\mathrm{td}^{+}$cells were $\mathrm{S} 100$ $\beta^{-}$Sox $2^{-} \mathrm{GFAP}^{-}$triple negative in $\mathrm{Vps} 35^{\text {Foxj1-CreER }}$ mice, which was undetectable in control mice (Fig. 10A,E). These results suggest that Vps35 in Foxj1 lineage cells at neonatal age is also necessary for EpC genesis/differentiation, but some EpCs lose their original identity without Vps35.

Increased cell proliferation and death in LV-SVZ regions of both Vps35 ${ }^{\text {GFAP-Cre }}$ and Vps35 $5^{\text {Foxj1-CreER }}$ mice

The reduced EpCs in Vps35 cKO mice could be due to decreased proliferation in EpC progenitors, increased cell death of EpCs, and/or impaired EpC differentiation. To test these possibilities, we first examined cell proliferation and death in E16.5 control and Vps $35^{\text {GFAP-Cre }}$ mice. BrdU was intraperitoneally injected twice into pregnant control and Vps35 GFAP-Cre mothers (at E16.5) before killing to assess cell proliferation (Fig. 11A). A slight increase in $\mathrm{BrdU}^{+}$cell density was detected in the LV region of Vps $35^{\text {GFAP-Cre }}$; Ai9 mice (Fig. $11 B, C$ ). However, the cell cycle exit $\left(\mathrm{BrdU}^{+} \mathrm{Ki}^{+} 7^{+} / \mathrm{BrdU}^{+}\right.$cells) was comparable between mutant and control mice (Fig. $11 B, C$ ). In addition, the number of $\mathrm{S} 100 \beta^{+}$cells in the LV-EpC region of Vps35 ${ }^{\mathrm{GFAP}-\mathrm{Cre}}$; Ai9 mice was slightly lower than that of controls (Fig. 11E,F). 


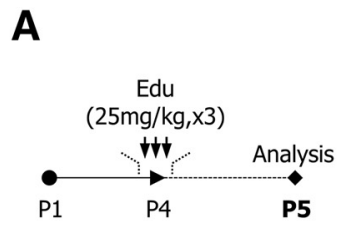

B LV-SVZ LV-EpC

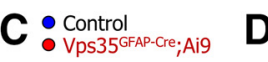

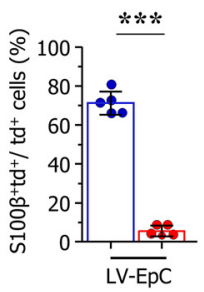

D

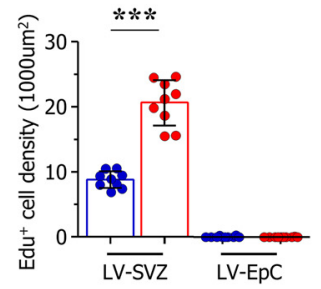

E

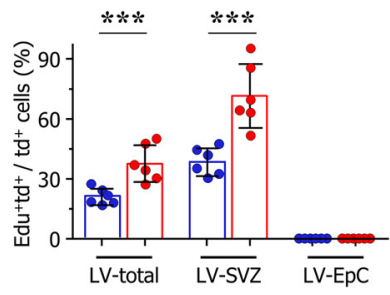

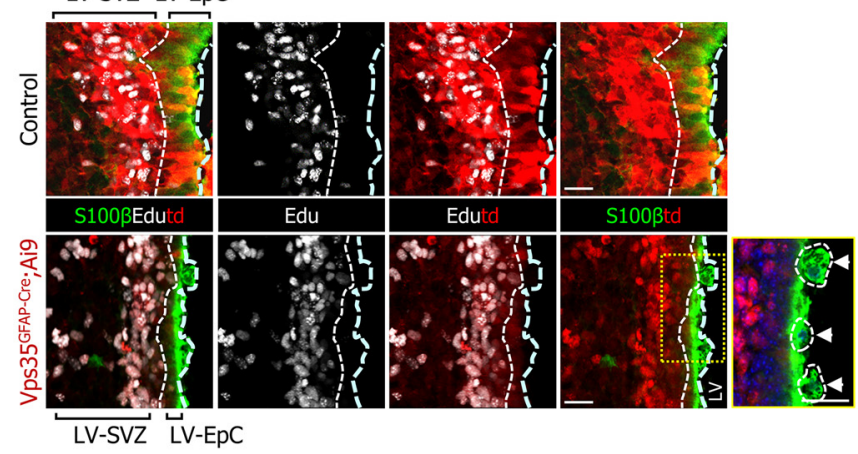

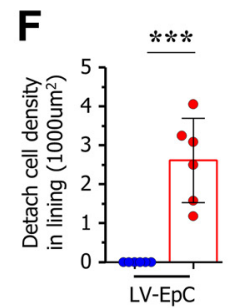

G

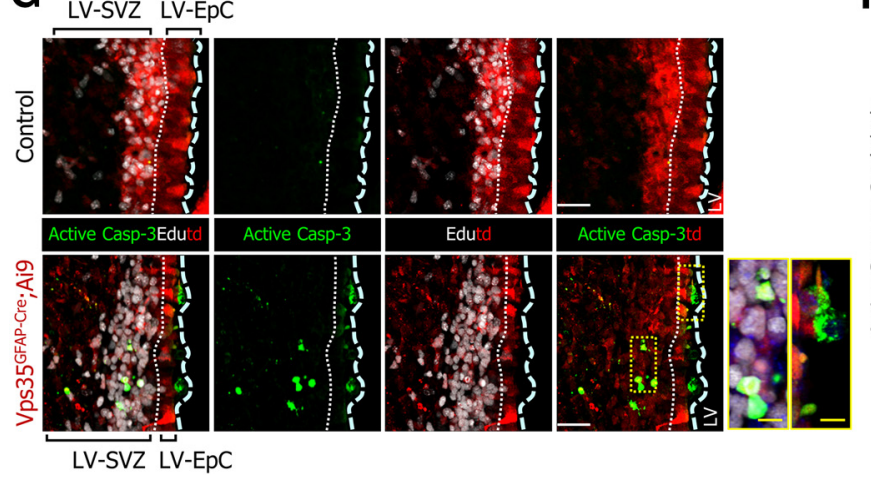

$\mathbf{H}$

- Control

- Vps35'GFAP-Cre;Ai9

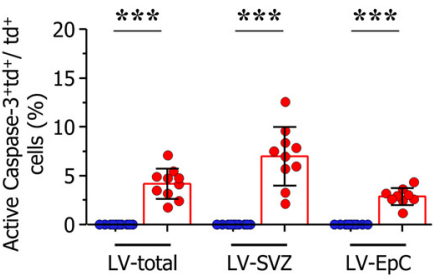

LV-SVZ LV-EpC

Figure 12. Increases in cell proliferation and death in ependymal regions of P5 Vps35 $5^{\text {GFAP-Cre. }}$; Ai9 mice. A, Illustration of experimental design. P4 control (GFAP-Cre; Ai9) and Vps35 GFAP-rre, Ai9 pups were injected with EdU for three times, the animals were killed at P5. B, Representative images of costaining of td (red), S100 $\beta$ (green), and EdU (white) in control and mutant mouse brain sections. LV is indicated. The dotted lines mark the regions of EpC and SVZ layers, respectively. Scale bar, $20 \mu \mathrm{m}$. C $-\boldsymbol{F}$, Quantifications of data in $\boldsymbol{B}$. The ratio of td ${ }^{+} S 100 \beta^{+}$cells over $\mathrm{td}^{+}$cells in indicated region $(\boldsymbol{C})$. The EdU ${ }^{+}$cell density in indicated regions $(\boldsymbol{D})$. The ratio of $\mathrm{td}^{+} \mathrm{EdU}^{+}$over $\mathrm{td}^{+}$cells $(\boldsymbol{E})$. The cell density of detached EpCs $(\boldsymbol{F})$. Data shown are mean \pm SEM; ${ }^{* * *} p<0.001$, Student's $t$ test. G, Representative images of coimmunostaining of activated Caspase 3 (green), EdU (white), and td (red) in control and Vps35 $5^{\text {GFAP-Cre }}$ LV-lining regions. The dotted lines mark the regions of LV-EpC layer and LV-SVZ layer. Scale bar, $20 \mu \mathrm{m}$. $\boldsymbol{H}$, Quantification of activated Caspase $3^{+} \mathrm{td}^{+}$over td ${ }^{+}$cells (\%) in indicated LV regions. Data shown are mean \pm SEM; ${ }^{* * *} p<0.01 ; n s$, no significance. Student's $t$ test.

The number of apoptotic cells (marked by active Caspase 3 ) was nearly undetectable in LV-EpC regions of both control and Vps35 ${ }^{\text {GFAP-Cre }}$; Ai9 mice (Fig. 11D,E). These results suggest little to weak effect on $\mathrm{RGC/EpC} \mathrm{precursor} \mathrm{cell} \mathrm{proliferation,} \mathrm{death,}$ and EpC differentiation in E16.5 Vps $35^{\text {GFAP-Cre }}$ embryos.

We next examined cell proliferation, cell death, and $\mathrm{S} 100 \beta^{+}$ EpCs in P5 control (GFAP-Cre; Ai9) and Vps $35^{\text {GFAP-Cre; }}$ Ai9 mice, which were injected with EdU at $\mathrm{P} 4$ for three times before killing (Fig. 12A). Again, $\mathrm{S} 100 \beta^{+} \mathrm{EpC}$ density and $\mathrm{S} 100 \beta^{+} \mathrm{td}^{+} /$ total $\mathrm{td}^{+}$cells were both reduced in the mutant LV lining/EpC regions (named as LV-EpC region; Fig. $12 B-D$ ), in line with the view for an impairment in EpC differentiation. Analyzing $\mathrm{EdU}^{+}$ cells found that they were largely $\mathrm{td}^{+}$, but $\mathrm{S} 100 \beta^{-}$(Fig. 12B), and distributed in the deep region from $S 100 \beta^{+}$LV-EpCs (named it as LV-SVZ region). These cells $\left(\mathrm{EdU}^{+} \mathrm{td}^{+} \mathrm{S} 100 \beta^{-}\right.$ cells) were markedly increased in the mutant mice (Fig. 12B,E), and are likely to be RGCs/RGC progenies/EpC progenitors. We also analyzed cell death by immunostaining analysis of active Caspase 3 , and an increase in active Caspase $3^{+}$cells in both mutant LV-EpC and LV-SVZ regions were detected (Fig. 12F-H).
Together, these results demonstrate increased cell proliferation and death, coupled with impaired EpC differentiation, in Vps $35^{\text {GFAP-Cre }}$ mice.

Finally, we examined cell proliferation, death, and $\mathrm{S} 100 \beta^{+}$ EpCs in P5 control and Vps35 $35^{\text {Foxj1-CreER }}$ mice. Mice were injected with tamoxifen at P1, then EdU at P4 for three times before killing (Fig. 13A). As expected, S100 $\beta^{+}$cells were much less in LV-EpC regions of P5 Vps35 $5^{\text {Foxj1-CreER }}$ mice (Fig. 13B). Both $\mathrm{EdU}^{+}$and active Caspase $3^{+}$cell densities were significantly increased largely in the LV-SVZ, but not the LV-EpC, region of $\mathrm{Vps}_{3} 5^{\text {Foxj1-CreER }}$ mice (Fig. $13 B-F$ ). Again, these $\mathrm{EdU}^{+}$ cells were S100 $\beta^{-}$(Fig. 13B). Taken together, these results demonstrate similar cell proliferation and death phenotypes in $\mathrm{Vps} 35^{\text {Foxj1-CreER }}$ mice as those in Vps $35^{\text {GFAP-Cre }}$ mice.

Local microglial activation that surrounds $\mathrm{LV}$ of $\mathrm{Vps} 35^{\text {Foxj1-CreER }}$ mice

In addition to EpCs, we examined microglia, the resident macrophage cells in the brain that are not derived from $\mathrm{GFAP}^{+}$RGCs or Foxj1-lineage. Using Iba1 to mark microglia in Vps35 $5^{\text {Foxj1-CreER; }}$ 
A

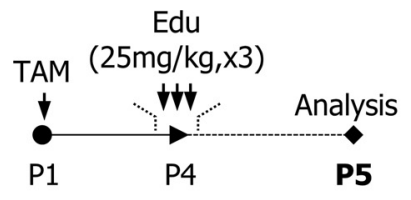

B LV-SVZ LV-EpC
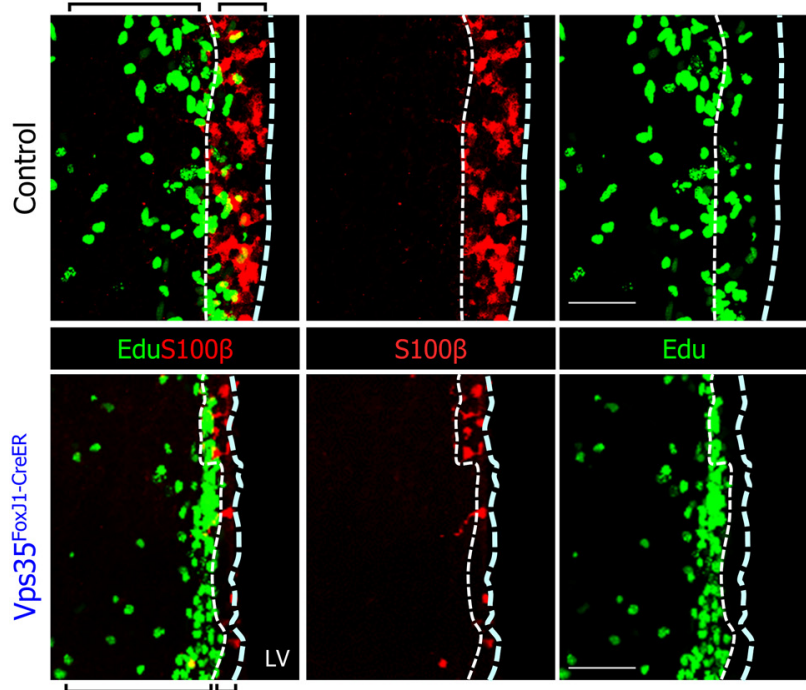

LV-SVZ LV-EpC

E
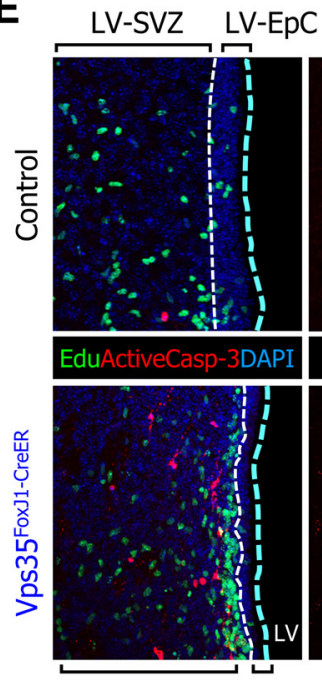

LV-SVZ
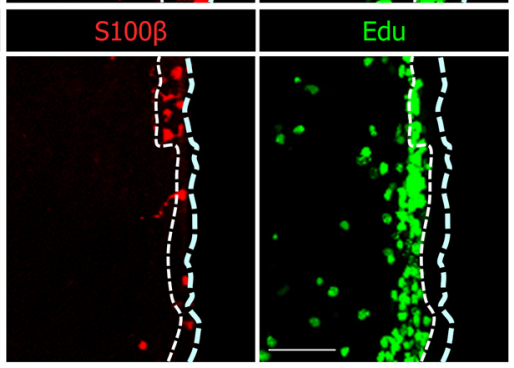

\section{(}
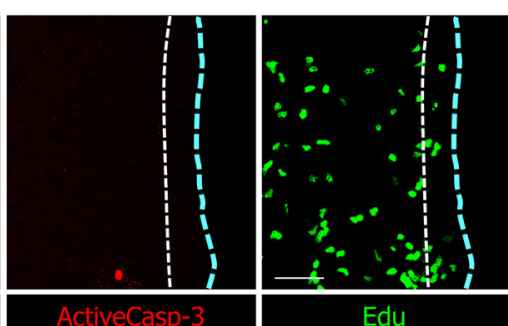

Edu
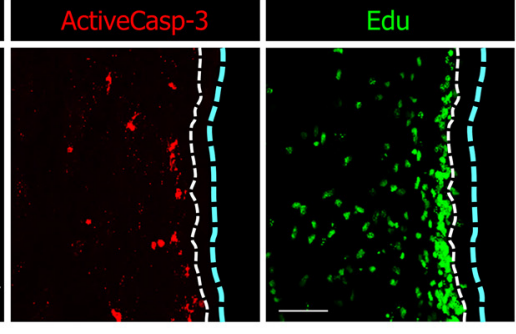

LV-EpC
C

- Control

- Vps35Foxj1-CreER

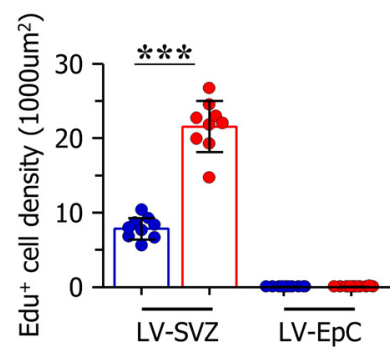

D

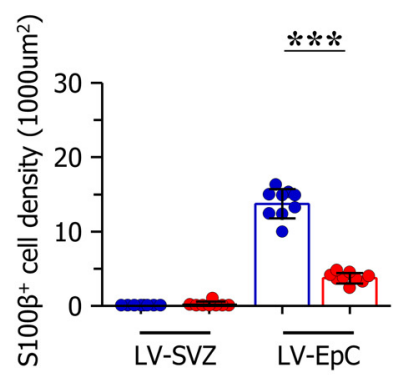

F

\section{- Control}

- Vps35Foxi1-CreER

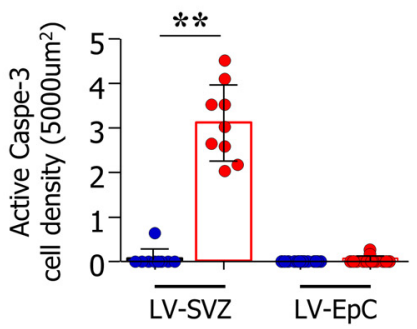

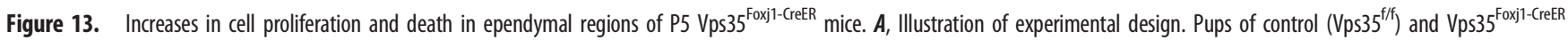
mice were injected with tamoxifen at P1, followed by EdU at P4 for three times, and killed at P5. $\boldsymbol{B}$, Representative images of coimmunostaining of $\mathrm{S} 100 \beta$ (red) and EdU (green) in control and Vps35 $5^{\text {Foxi-CreER }}$ brain sections. LV is indicated, and the dotted lines mark the regions of LV-EpC and LV-SVZ, respectively. Scale bar, $40 \mu \mathrm{m}$. C, D, Quantifications of data in $\boldsymbol{B}$. EdU ${ }^{+}$cell density in indicated regions $(\boldsymbol{C}) ; S 100 \beta^{+}$cell density in indicated regions (D). Data shown are mean \pm SEM; ${ }^{* * *} p<0.001$, Student's $t$ test. $\boldsymbol{E}$, Representative images of coimmunostaining of activated Caspase 3 (red) and EdU (green) in control and Vps35 $5^{\text {Foxji-creeR }}$ LV-lining regions. LV is indicated, and the dotted lines mark the regions of LV-EpC and LV-SVZ layers. Scale bar, $40 \mu \mathrm{m} . \boldsymbol{F}$, Quantification of activated Caspase $3^{+}$cell density in indicated LV regions. Data shown are mean $\pm S E M ;{ }^{* *} p<0.01$, Student's $t$ test.

Ai9 and control (Foxj1-CreER; Ai9) mice, to our surprise, more $\mathrm{Ibal}^{+}$microglia were detected in the ependymal layer of LV (LVEpCs) in P7 Vps35 ${ }^{\text {Foxj1-CreER }}$ mutant mice, which was undetectable in their littermate control mice (Fig. 14A). The density of $\mathrm{Ibal}^{+}$ microglia was also increased at the area of LV-SVZ, but not in the area $400 \mu \mathrm{m}$ away from LV-EpC, of Vps35 $5^{\text {Foxj1-CreER }}$ mice (Fig. $14 A-C)$. In addition, many of these $\mathrm{Ibal}^{+}$microglia appeared to be activated locally, as they were positive for CD11b, a marker for activated microglia (Fig. 14D,E), and displayed morphologic alterations (e.g., enlarged soma volumes, but reduced processes) as microglial activation (Fig. 14F,G). These results thus suggest that Vps35 KO in Foxj1-Cre ${ }^{+}$cells results in a local microglial activation in a cell nonautonomous manner.

Amelioration of hydrocephalus and restore of EpCs in Vps35 $5^{\text {Foxj1-CreER }}$ mice by depletion of microglial cells

Next, we asked whether such a local microglial activation contributes to the hydrocephalus in Vps35 $5^{\text {Foxj1-CreER }}$ mice. To this end, Vps35 $5^{\text {Foxj1-CreER }}$ and control pups, after exposure to the tamoxifen at P1, were injected with PLX3397 (20 mg/kg, at P2, P4, 
A

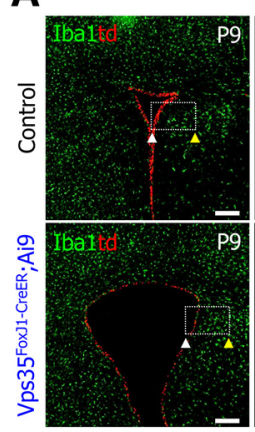

D

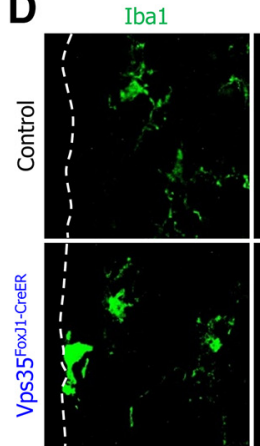

LV-EpC

LV-SVZ

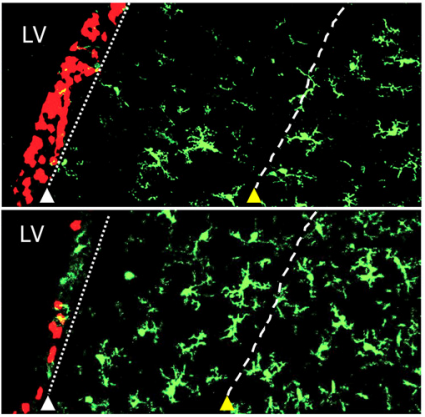

CD11b

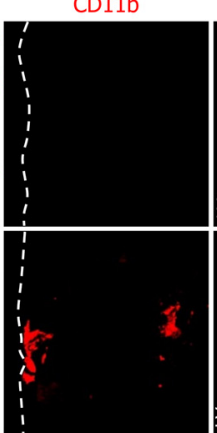

Iba1CD11b

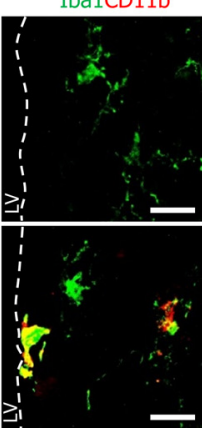

B

$$
\begin{aligned}
& \text { - Control } \\
& \text { - Vps35Foxj1-Creer;Ai9 }
\end{aligned}
$$

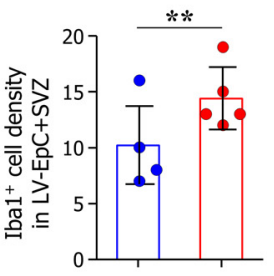

C

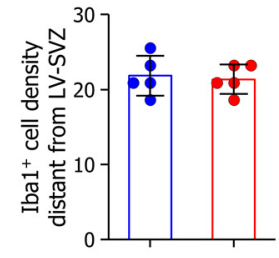

G
E

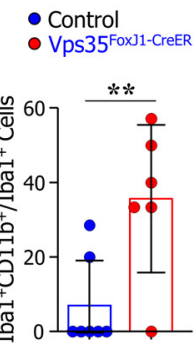

F

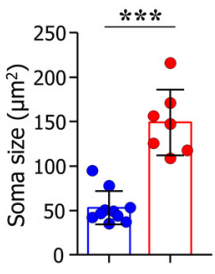

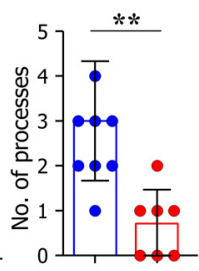

Figure 14. Local microglial activation in Vps35 $5^{\mathrm{Foxj} j-\text { CreeR }} \mathrm{LV}$ lining and adjacent regions. $\boldsymbol{A}$, Representative co-immunostaining images of brain sections of P9 control (Foxj1-CreER; Ai9) and Vps35 $5^{\text {Foxi-CreER }}$; Ai9 mice using indicated antibodies. LV-EpC and LV-RGC regions are indicated. Scale bar, $200 \mu \mathrm{m}$. B, C, Quantifications of data in $\boldsymbol{A}$. The Iba ${ }^{+}$cell density in LV-EpC and LV$\mathrm{RGC}$ regions $(\boldsymbol{B})$; and the Iba1 ${ }^{+}$cell density that is distal to LV-RGC (C). Data shown are mean \pm SEM from four mice in each group; ${ }^{* *} p<0.01 ;$ ns, no significance, Student's $t$ test. $\boldsymbol{D}$,

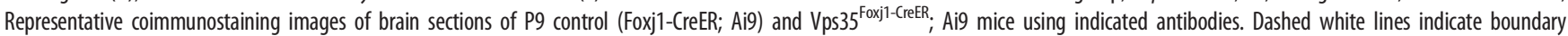
between the LV lumen and brain parenchyma. Scale bar, $20 \mu \mathrm{m}$. $\boldsymbol{E}$, Quantification of the percentage of Iba $1^{+} \mathrm{CD}_{11 \mathrm{~b}^{+}}$cells over Iba1 ${ }^{+}$cells in regions close to $\mathrm{LV}$ lining. Data shown are mean \pm SEM from six mice in each group; ${ }^{* *} p<0.01$, Student's $t$ test. $\boldsymbol{F}, \boldsymbol{G}$, Quantifications of the soma size $(\boldsymbol{F})$ and number of processes per cell (G). Data shown are mean \pm SEM from $>30$ cells in each group; ${ }^{* *} p<0.001$, Student's $t$ test.

and P6) to deplete microglia, and at P7, these pubs were examined (Fig. 15A). PLX3397 is an antagonist of colony-stimulating factor 1 receptor (CSF1R), which is often used to block microglial proliferation and survival, thus depleting microglia (Elmore et al., 2014; Szalay et al., 2016). Indeed, on PLX3397 treatment, $\mathrm{Ibal}^{+}$microglia close to the LVs were largely depleted in both control and Vps35 $5^{\text {Foxj1-CreER }}$ mice (Fig. 15B,C).

We then examined $\mathrm{S} 100 \beta^{+}$EpCs in control and Vps35 $5^{\text {Foxjl-CreER }}$ mice in response to PLX3397. While PLX3397 treatment had little effect on $\mathrm{S} 100 \beta^{+}$EpCs number in control mice, these $\mathrm{S} 100 \beta^{+}$EpCs were markedly elevated in Vps35 ${ }^{\text {Foxj1-CreER }}$ mice by PLX3397 treatment, as compared with that of vehicle treatment (Fig. 15B,D). In addition to $\mathrm{S} 100 \beta^{+}$EpCs, we examined $\mathrm{GFAP}^{+}$cells in control and $\mathrm{Vps} 35^{\text {Foxj1-CreER }}$ mice in response to PLX3397. In control mice, $\mathrm{GFAP}^{+}$fibers were initiated from SVZ and projected to brain parenchyma as a parallel distribution pattern, a morphologic feature of RGCs (Fig. 15E). However, in Vps35 $5^{\text {Foxj1-CreER }}$ mice, such a parallel distribution of $\mathrm{GFAP}^{+}$fibers were disrupted, exhibiting morphologic features of reactive astrocytes (Fig. 15E). Interestingly, this GFAP phenotype was also largely diminished in $\mathrm{Vps} 35^{\text {Foxjl-CreER }}$ mice by PLX3397 treatment (Fig. 15E,F).

We next examined LV structures in brain sections of control and Vps35 mutant mice by Nissl staining analysis. While Vps35 ${ }^{\text {Foxj1-CreER }}$ mice treated with the vehicle developed enlarged LVs, a marked reduction in LV area was noted in Vps35 $5^{\text {Foxj1-CreER }}$ mice injected with PLX3397 (Fig. 15G,H). Taken together, these results suggest that PLX3397 depletion of microglial cells in Vps35 $5^{\text {Foxj1-CreER }}$ mice is sufficient to abolish nearly all of the deficits in $\mathrm{Vps} 35^{\text {Foxj1-CreER }}$ mice, demonstrating critical pathologic functions of locally activated microglia in EpC homeostasis and hydrocephalus progression.

\section{Discussion}

VPS35, a key component of retromer complex, plays an essential role in retrieval of transmembrane proteins from endosomes to trans-Golgi networks (Hierro et al., 2007; Collins, 2008; Seaman, 2012; Burd and Cullen, 2014). Dysfunctional VPS35 or retromer is believed to be risk factors for neurodegenerative disorders, including AD and PD (Zimprich et al., 2011; Small and Petsko, 2015; Williams et al., 2017; Vagnozzi and Praticò, 2019). Thus, it is of interest to investigate Vps35's physiological functions in different types of brain cells. Here, we investigated its role in EpCs, one type of glial cells in the brain. We found that Vps35 is abundantly expressed in EpCs, where it is required for EpC differentiation and ciliogenesis, crucial processes for maintaining CSF homeostasis and preventing hydrocephalus. Additionally, Vps35 in EpCs is necessary to prevent local microglial activation, which contributes to EpC homeostasis and hydrocephalus development. Finally, our results suggest that the hydrocephalus in Vps35 KO mice may not be a consequence of brain shrinkage/atrophy, but a result from the impaired EpC differentiation and function and the activated microglia. These observations lead to a working model depicted in Figure 16 for ependymal Vps35's function in hydrocephalus development.

Several lines of evidence have pointed out VPS35/retromer's function in EpC differentiation and ciliogenesis. First, VPS35 as well as retromer complex proteins [e.g., sortin nexin 27 (SNX27)] are highly expressed in developing EpCs (Fig. 3; Wang 
A

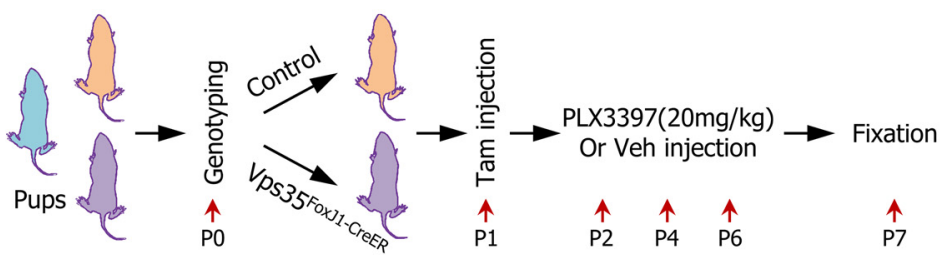

B S100ß Ibal

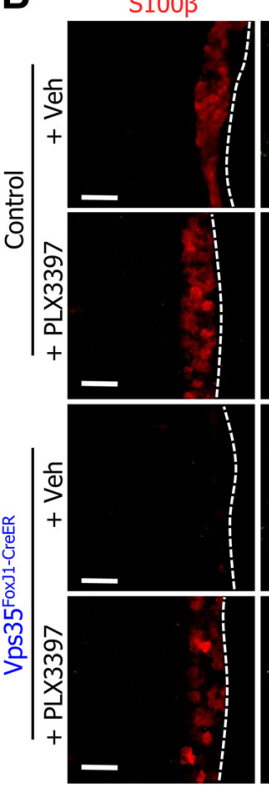

C

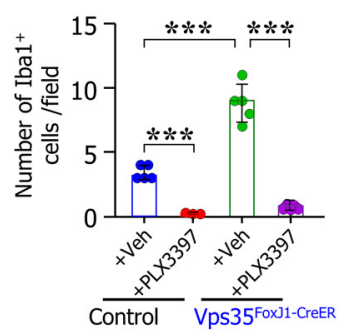

G

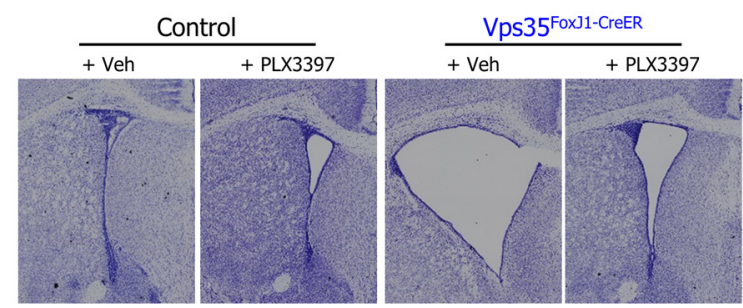

E

Iba1

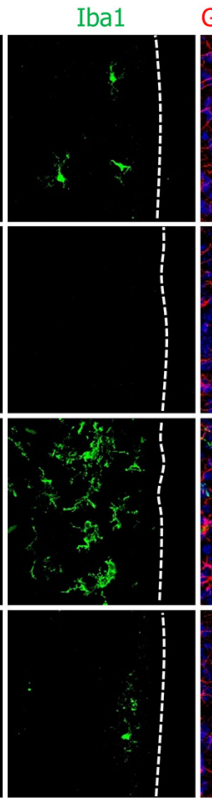

GFAPIba1DAPI

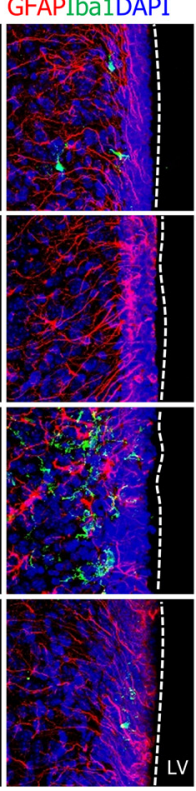

F

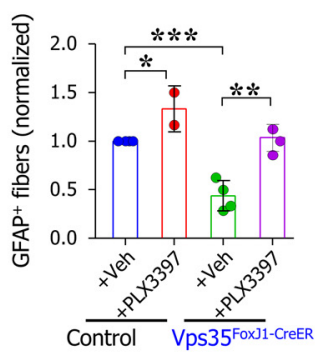

H

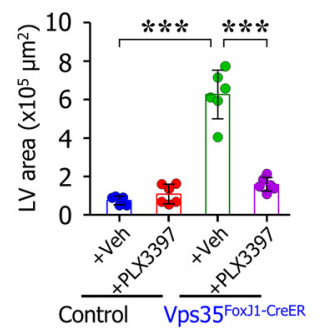

Figure 15. Increase of EpCs and attenuation of hydrocephalus-like deficits in Vps35 $5^{\text {Foxi-creer }}$ mice depleting microglia. $\boldsymbol{A}$, Illustration of experimental design. Neonatal pups exposed to tam at P1 were injected with PLX397 (20 mg/kg) for three times at P2, P4, and P6. The mouse brains are fixed at P7 and subjected to below phenotype analyses. B, Representative co-immunostaining images of $\mathrm{S} 100 \beta^{+}$and Iba1 ${ }^{+}$cells in P7 control and Vps33 $5^{\text {Foxj-Creer }}$ mice with PLX3397 or vehicle (veh) treatments. Scale bar, $20 \mu \mathrm{m}$. C, Quantification of the number of Iba ${ }^{+}$cells per area in regions close to LV lining. $\boldsymbol{D}$, Quantification of the number of $\mathrm{S} 100 \beta^{+}$cells per area in LV lining. In $\boldsymbol{C}, \boldsymbol{D}$, data shown are mean \pm SEM from six mice in each group; ns, no significance; ${ }^{* *} p<$ $0.01,{ }^{* * *} p<0.001$, two-way ANOVA with Bonferroni correction post hoc test. $\boldsymbol{E}$, Representative images of GFAP ${ }^{+}$and $\mathrm{Iba1}^{+}$cells in LV regions of P7 control and Vps35 $5^{\mathrm{Foxj} j-\text {-CreER }}$ mice treated with PLX3397 or veh. Scale bar, $20 \mu \mathrm{m}$. $F$, Quantification of the number of GFAP ${ }^{+}$fibers per area. GFAP ${ }^{+}$fibers that are initiated in LV lining and projected to the brain parenchyma were quantified. Data are normalized with the value of control + Veh group as 1, and shown as mean \pm SEM from six PSD mice in each group; ${ }^{*} p<0.05,{ }^{* *} p<0.01$, ${ }^{* * *} p<0.001$; ns, no significance, two-way ANOVA with Bonferroni correction post hoc test. $\boldsymbol{G}$, Nissl staining of P7 control and Vps35 $5^{\text {Foxj-CreER }}$ mice treated with PLX3397 or veh. The LV and surrounding regions are shown. $\boldsymbol{H}$, Quantification of LV area of indicated mice. Data shown are mean \pm SEM from three mice in each group; ${ }^{* * *} p<0.001$, two-way ANOVA with Bonferroni correction post hoc test.

et al., 2016b). Second, knocking out Vps35 either in RGCs at embryonic stage (by hGFAP-Cre) or in EpC progenitors at neonatal age (by Foxj1-Cre) leads to reduced EpCs and their ciliogenesis (Figs. 6, 7). Third, in both Vps35 ${ }^{\text {GFAP-Cre }}$; Ai9 and Vps35 ${ }^{\text {Foxil-CreER; }}$
Ai9 mice, tracing the cell fate derived from $\mathrm{Cre}^{+}\left(\mathrm{td}^{+}\right)$cells has shown a reduction in $\operatorname{td}^{+}$S100 $\beta^{+}$EpCs (Figs. 8-10). Finally, in agreement with our results are the observations of the reduced $\mathrm{EpC}$ differentiation and ciliogenesis in SNX27-/- mice (Wang et al., 


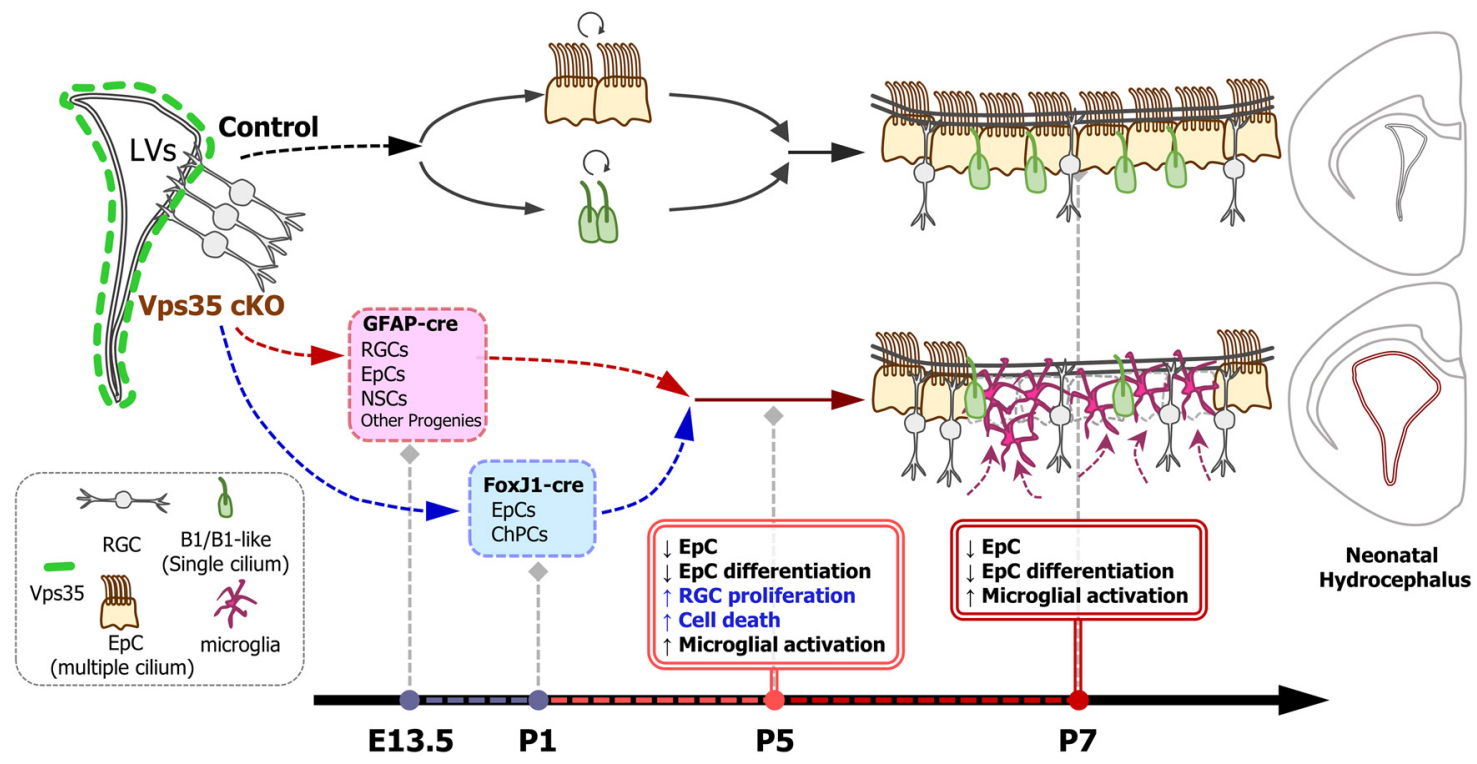

Figure 16. Summary and a working model of Vps35's functions in regulating EpC genesis.

2016b). Note that SNX27 is another component of retromer complex. These observations support the view for VPS35/retromer's function in promoting EpC differentiation and ciliogenesis.

In addition to EpC differentiation, Vps35 may play important roles in regulating cell proliferation and survival in cells largely located in LV-SVZ regions, as both Vps $35^{\text {GFAP-Cre }}$ and Vps35 $5^{\text {Foxj1-CreER }}$ mice (at age of P5) show increases in $\mathrm{EdU}^{+}$ and active Caspase $3^{+}$cells in this region (Figs. 12, 13). These increased proliferative cells are $\mathrm{S} 100 \beta^{-}$, but GFAP-Cre ${ }^{+}$, implicating that they are likely to be RGCs, EpC precursor cells, and the RGC subsequent progeny-transit amplifying cells and neuroblasts. Whereas our results suggest that Vps35 expression in GFAP-Cre ${ }^{+}$cells is necessary for promoting EpC differentiation and preventing cell proliferation and death in cells located at the LV-SVZ region, the observations in $\mathrm{Vps} 35^{\text {Foxj1-CreER }}$ mice indicate that ependymal Vps35 (in Foxj1-Cre ${ }^{+}$cells) regulates cell proliferation and death in cells in the LV-SVZ region in a cell non-autonomous manner. The underlying mechanism(s) may be different, which remain to be addressed in future experiments. A difference in active Caspase $3^{+}$cells was noted between Vps35 GFAP-Cre and Vps $35^{\text {Foxj1-CreER }}$ mice. The active Caspase $3^{+}$cell death was detected not only in cells in LV-SVZ region, but also in S100 $\beta^{+}$LV-EpCs of Vps35 ${ }^{\text {GFAP-Cre }}$, which was not observed in $\mathrm{Vps} 35^{\text {Foxj1-CreER }}$, mice (Figs. 12, 13). Another different phenotype is that the remaining EpCs in Vps35 ${ }^{\mathrm{GFAP}-\mathrm{Cre}}$, but not Vps35 ${ }^{\text {Foxj1-Cre }}$, mice are largely disorganized (Figs. 8, 16). These results suggest different cellular mechanisms that may underlie the EpC-loss between Vps35 $5^{\text {GFAP-Cre }}$ and Vps35 $5^{\text {Foxj1-CreER }}$ mice, and also implicate that both RGCs and EpCs are tightly associated or linked, and they may regulate each other's cell fate, function, and survival.

It is of interest to note that microglial cells surrounding LVs of $\mathrm{Vps} 35^{\text {Foxj1-CreER }}$ mice became activated (Fig. 14), raising a question of how Vps35-loss in EpCs causes microglial activation. Whereas the exact underlying cellular and molecular mechanisms remain unclear, we speculate that Vps35 in EpC lineage cells may play a negative role in astrogliosis and its associated microglial activation. This speculation is in light of the observation that a temporal and spatial association exists between microglial activation and astrogliosis (viewed by $\mathrm{GFAP}^{+}$reactive astrocyte-like morphology) in $\mathrm{Vps} 35^{\text {Foxj1-CreER }}$ mice (Fig. 15). However, this speculation requires additional experimental evidence.

The activated microglia have significant contributions to the development of the hydrocephalus in $\mathrm{Vps} 35^{\text {Foxj1-CreER }}$ mice. They are not only temporally, but also spatially/locally, associated with the impaired EpCs in the mutant LVs (Fig. 14). Depletion of microglia in Vps35 $5^{\text {Foxj1-CreER }}$ mice by CSF1R antagonist, PLX3397, attenuates the hydrocephalus-associated deficits, which include decreased EpCs, increased $\mathrm{GFAP}^{+}$reactive astrocytes, and enlarged LVs (Fig. 15). Many literature reports present evidence for the beneficial effects of microglial depletion in AD mouse models (Waisman et al., 2015; Hansen et al., 2018). Several pathologic facets of $\mathrm{AD}$, including tau propagation, synaptic stripping, neuronal loss, and cognitive decline, can be relieved by depletion of microglia (Spangenberg et al., 2016; Hansen et al., 2018). These reports, in line with our results, suggest that targeting/inhibiting microglia-evoked "toxic effect" (likely to be neuro-inflammation) may be beneficial for potential therapeutics of not only $\mathrm{AD}$, but also hydrocephalus.

Clinically, NPH is often associated with patients with AD/PD. In line with this view are observations by brain imaging examinations (e.g., MRI) that frequently show enlarged ventricles in these patients (Nestor et al., 2008; Frisoni et al., 2010; Camicioli et al., 2011; Mak et al., 2017). However, little is known regarding their relationship or the underlying mechanisms for their comorbidity. One hypothesis is proposed that the enlarged ventricles or NPH may be a consequence of brain shrinkage or neurodegeneration in $\mathrm{AD} / \mathrm{PD}$ patients. Another hypothesis is that both NPH and neurodegenerative disorders (AD or PD) are parallel diseases with high comorbidity (Camicioli et al., 2011; Espay et al., 2017; Allali et al., 2018). Here, we found that the hydrocephalus occurs in Vps35 $5^{\text {GFAP-Cre }}$ and Vps $35^{\text {EMX1-Cre }}$ mice, but not in Vps $35^{\text {NeuroD6-Cre }}$ mice, although all three Vps 35 mutant mouse lines show brain atrophy-like deficits (e.g., thinner cortical brains and smaller hippocampus; Fig. 1; data not shown). In addition, selective knocking out Vps35 in postnatal EpCs (Vps35 $5^{\text {Foxj1-CreER }}$ mice) is sufficient to induce hydrocephalus (Fig. 4). In light of these observations, we speculate that the high comorbidity 
between NPH and AD/PD may result from some shared genetic risk factors (e.g., Vps35) that are involved not only in neurodegeneration, but also dysfunctional EpC associated hydrocephalus. Further testing this view may reveal insights into their comorbidity.

In summary, the results presented in this paper not only demonstrate Vps35/retromer's functions in EpC differentiation and ciliogenesis, but also identify an important contribution of locally activated microglia to EpC homeostasis and hydrocephalus development, revealing a potential strategy for the therapy of hydrocephalus.

\section{References}

Allali G, Laidet M, Armand S, Assal F (2018) Brain comorbidities in normal pressure hydrocephalus. Eur J Neurol 25:542-548.

Appel JR, Ye S, Tang F, Sun D, Zhang H, Mei L, Xiong WC (2018) Increased microglial activity, impaired adult hippocampal neurogenesis, and depressive-like behavior in microglial Vps35-depleted mice. J Neurosci 38:5949-5968.

Burd C, Cullen PJ (2014) Retromer: a master conductor of endosome sorting. Cold Spring Harb Perspect Biol 6:a016774.

Camicioli R, Sabino J, Gee M, Bouchard T, Fisher N, Hanstock C, Emery D, Martin WR (2011) Ventricular dilatation and brain atrophy in patients with Parkinson's disease with incipient dementia. Mov Disord 26:14431450.

Collins BM (2008) The structure and function of the retromer protein complex. Traffic 9:1811-1822.

Del Bigio MR (2010) Ependymal cells: biology and pathology. Acta Neuropathol 119:55-73.

Delgehyr N, Meunier A, Faucourt M, B, Grau M, Strehl L, Janke C, Spassky N (2015) Ependymal cell differentiation, from monociliated to multiciliated cells. Methods Cell Biol 127:19-35.

Deutschlander A, Ross OA, Wszolek ZK (1993) Vps35-related Parkinson disease. In: Gene reviews (Adam MP, Ardinger HH, Pagon RA, Wallace SE, Bean LJH, Stephens K, Amemiya A, eds). Seattle: University of Washington, Seattle.

Doetsch F, Caillé I, Lim DA, García-Verdugo JM, Alvarez-Buylla A (1999) Subventricular zone astrocytes are neural stem cells in the adult mammalian brain. Cell 97:703-716.

Elmore MR, Najafi AR, Koike MA, Dagher NN, Spangenberg EE, Rice RA, Kitazawa M, Matusow B, Nguyen H, West BL, Green KN (2014) Colonystimulating factor 1 receptor signaling is necessary for microglia viability, unmasking a microglia progenitor cell in the adult brain. Neuron 82:380397.

Espay AJ, Da Prat GA, Dwivedi AK, Rodriguez-Porcel F, Vaughan JE, Rosso M, Devoto JL, Duker AP, Masellis M, Smith CD, Mandybur GT, Merola A, Lang AE (2017) Deconstructing normal pressure hydrocephalus: ventriculomegaly as early sign of neurodegeneration. Ann Neurol 82:503513.

Fliegauf M, Benzing T, Omran H (2007) When cilia go bad: cilia defects and ciliopathies. Nat Rev Mol Cell Biol 8:880-893.

Frisoni GB, Fox NC, Jack CR Jr, Scheltens P, Thompson PM (2010) The clinical use of structural MRI in Alzheimer disease. Nat Rev Neurol 6:67-77.

Fuentealba LC, Rompani SB, Parraguez JI, Obernier K, Romero R, Cepko CL, Alvarez-Buylla A (2015) Embryonic origin of postnatal neural stem cells. Cell 161:1644-1655.

Goebbels S, Bormuth I, Bode U, Hermanson O, Schwab MH, Nave KA (2006) Genetic targeting of principal neurons in neocortex and hippocampus of NEX-Cre mice. Genesis 44:611-621.

Gorski JA, Talley T, Qiu M, Puelles L, Rubenstein JL, Jones KR (2002) Cortical excitatory neurons and glia, but not GABAergic neurons, are produced in the Emx1-expressing lineage. J Neurosci 22:6309-6314.

Guirao B, Meunier A, Mortaud S, Aguilar A, Corsi JM, Strehl L, Hirota Y, Desoeuvre A, Boutin C, Han YG, Mirzadeh Z, Cremer H, Montcouquiol M, Sawamoto K, Spassky N (2010) Coupling between hydrodynamic forces and planar cell polarity orients mammalian motile cilia. Nat Cell Biol 12:341-350.

Hansen DV, Hanson JE, Sheng M (2018) Microglia in Alzheimer's disease. J Cell Biol 217:459-472.
Harbour ME, Breusegem SY, Antrobus R, Freeman C, Reid E, Seaman MN (2010) The cargo-selective retromer complex is a recruiting hub for protein complexes that regulate endosomal tubule dynamics. J Cell Sci 123:3703-3717.

Hierro A, Rojas AL, Rojas R, Murthy N, Effantin G, Kajava AV, Steven AC, Bonifacino JS, Hurley JH (2007) Functional architecture of the retromer cargo-recognition complex. Nature 449:1063-1067.

Jacquet BV, Salinas-Mondragon R, Liang H, Therit B, Buie JD, Dykstra M, Campbell K, Ostrowski LE, Brody SL, Ghashghaei HT (2009) Foxj1-dependent gene expression is required for differentiation of radial glia into ependymal cells and a subset of astrocytes in the postnatal brain. Development 136:4021-4031.

Kahle KT, Kulkarni AV, Limbrick DD Jr, Warf BC (2016) Hydrocephalus in children. Lancet 387:788-799.

Kousi M, Katsanis N (2016) The genetic basis of hydrocephalus. Annu Rev Neurosci 39:409-435.

Louvi A, Grove EA (2011) Cilia in the CNS: the quiet organelle claims center stage. Neuron 69:1046-1060.

Madisen L, Zwingman TA, Sunkin SM, Oh SW, Zariwala HA, Gu H, Ng LL, Palmiter RD, Hawrylycz MJ, Jones AR, Lein ES, Zeng H (2010) A robust and high-throughput Cre reporting and characterization system for the whole mouse brain. Nat Neurosci 13:133-140.

Mak E, Su L, Williams GB, Firbank MJ, Lawson RA, Yarnall AJ, Duncan GW, Mollenhauer B, Owen AM, Khoo TK, Brooks DJ, Rowe JB, Barker RA, Burn DJ, O'Brien JT (2017) Longitudinal whole-brain atrophy and ventricular enlargement in nondemented Parkinson's disease. Neurobiol Aging 55:78-90

Mirzadeh Z, Merkle FT, Soriano-Navarro M, Garcia-Verdugo JM, AlvarezBuylla A (2008) Neural stem cells confer unique pinwheel architecture to the ventricular surface in neurogenic regions of the adult brain. Cell Stem Cell 3:265-278

Muthusamy N, Vijayakumar A, Cheng G Jr, Ghashghaei HT (2014) A knock-in Foxj1(CreERT2::GFP) mouse for recombination in epithelial cells with motile cilia. Genesis 52:350-358.

Nestor SM, Rupsingh R, Borrie M, Smith M, Accomazzi V, Wells JL, Fogarty J, Bartha R; the Alzheimer's Disease Neuroimaging Initiative (2008) Ventricular enlargement as a possible measure of Alzheimer's disease progression validated using the Alzheimer's disease neuroimaging initiative database. Brain 131:2443-2454.

O'Leary CJ, Nourse CC, Lee NK, White A, Langford M, Sempert K, Cole SJ, Cooper HM (2017) Neogenin recruitment of the WAVE regulatory complex to ependymal and radial progenitor adherens junctions prevents hydrocephalus. Cell Rep 20:370-383.

Ohata S, Nakatani J, Herranz-Pérez V, Cheng J, Belinson H, Inubushi T, Snider WD, García-Verdugo JM, Wynshaw-Boris A, Alvarez-Buylla A (2014) Loss of Dishevelleds disrupts planar polarity in ependymal motile cilia and results in hydrocephalus. Neuron 83:558-571.

Rovelet-Lecrux A, Charbonnier C, Wallon D, Nicolas G, Seaman MN, Pottier C, Breusegem SY, Mathur PP, Jenardhanan P, Le Guennec K, Mukadam AS, Quenez O, Coutant S, Rousseau S, Richard AC, Boland A, Deleuze JF, Frebourg T, Hannequin D, Campion D, et al. (2015) De novo deleterious genetic variations target a biological network centered on $\mathrm{A} \beta$ peptide in early-onset Alzheimer disease. Mol Psychiatry 20:1046-1056.

Seaman MN (2012) The retromer complex - endosomal protein recycling and beyond. J Cell Sci 125:4693-4702.

Shimada IS, Acar M, Burgess RJ, Zhao Z, Morrison SJ (2017) Prdm16 is required for the maintenance of neural stem cells in the postnatal forebrain and their differentiation into ependymal cells. Genes Dev 31:11341146.

Shprecher D, Schwalb J, Kurlan R (2008) Normal pressure hydrocephalus: diagnosis and treatment. Curr Neurol Neurosci Rep 8:371-376.

Small SA, Petsko GA (2015) Retromer in Alzheimer disease, Parkinson disease and other neurological disorders. Nat Rev Neurosci 16:126-132.

Spangenberg EE, Lee RJ, Najafi AR, Rice RA, Elmore MR, Blurton-Jones M, West BL, Green KN (2016) Eliminating microglia in Alzheimer's mice prevents neuronal loss without modulating amyloid- $\beta$ pathology. Brain 139:1265-1281

Spassky N, Merkle FT, Flames N, Tramontin AD, García-Verdugo JM, Alvarez-Buylla A (2005) Adult ependymal cells are postmitotic and are derived from radial glial cells during embryogenesis. J Neurosci 25:1018. 
Szalay G, Martinecz B, Lénárt N, Környei Z, Orsolits B, Judák L, Császár E, Fekete R, West BL, Katona G, Rózsa B, Dénes Á (2016) Microglia protect against brain injury and their selective elimination dysregulates neuronal network activity after stroke. Nat Commun 7:11499.

Tang FL, Liu W, Hu JX, Erion JR, Ye J, Mei L, Xiong WC (2015a) Vps35 deficiency or mutation causes dopaminergic neuronal loss by impairing mitochondrial fusion and function. Cell Rep 12:1631-1643.

Tang FL, Erion JR, Tian Y, Liu W, Yin DM, Ye J, Tang B, Mei L, Xiong WC (2015b) Vps35 in dopamine neurons is required for endosome-to-Golgi retrieval of Lamp2a, a receptor of chaperone-mediated autophagy that is critical for $\alpha$-synuclein degradation and prevention of pathogenesis of Parkinson's disease. J Neurosci 35:10613-10628.

Tang FL, Zhao L, Zhao Y, Sun D, Zhu XJ, Mei L, Xiong WC (2020) Coupling of terminal differentiation deficit with neurodegenerative pathology in Vps35-deficient pyramidal neurons. Cell Death Differ. Advance online publication. Retrieved January 6, 2020. doi: 10.1038/s41418-019-0487-2.

Tissir F, Qu Y, Montcouquiol M, Zhou L, Komatsu K, Shi D, Fujimori T, Labeau J, Tyteca D, Courtoy P, Poumay Y, Uemura T, Goffinet AM (2010) Lack of cadherins Celsr2 and Celsr3 impairs ependymal ciliogenesis, leading to fatal hydrocephalus. Nat Neurosci 13:700-707.

Tsika E, Glauser L, Moser R, Fiser A, Daniel G, Sheerin UM, Lees A, Troncoso JC, Lewis PA, Bandopadhyay R, Schneider BL, Moore DJ (2014) Parkinson's disease-linked mutations in Vps35 induce dopaminergic neurodegeneration. Hum Mol Genet 23:4621-4638.

Tully HM, Dobyns WB (2014) Infantile hydrocephalus: a review of epidemiology, classification and causes. Eur J Med Genet 57:359-368.

Vagnozzi AN, Praticò D (2019) Endosomal sorting and trafficking, the retromer complex and neurodegeneration. Mol Psychiatry 24:857868.

Vilarino-Guell C (2011) Vps35 mutations in Parkinson disease. Am J Hum Genet 89:162-167.
Voigt T (1989) Development of glial cells in the cerebral wall of ferrets: direct tracing of their transformation from radial glia into astrocytes. J Comp Neurol 289:74-88

Waisman A, Ginhoux F, Greter M, Bruttger J (2015) Homeostasis of microglia in the adult brain: review of novel microglia depletion systems. Trends Immunol 36:625-636.

Wang CL, Tang FL, Peng Y, Shen CY, Mei L, Xiong WC (2012) Vps35 regulates developing mouse hippocampal neuronal morphogenesis by promoting retrograde trafficking of BACE1. Biol Open 1:1248-1257.

Wang W, Wang X, Fujioka H, Hoppel C, Whone AL, Caldwell MA, Cullen PJ, Liu J, Zhu X (2016a) Parkinson's disease-associated mutant Vps35 causes mitochondrial dysfunction by recycling DLP1 complexes. Nat Med 22:54-63.

Wang X, Zhou Y, Wang J, Tseng IC, Huang T, Zhao Y, Zheng Q, Gao Y, Luo H, Zhang X, Bu G, Hong W, Xu H (2016b) SNX27 deletion causes hydrocephalus by impairing ependymal cell differentiation and ciliogenesis. J Neurosci 36:12586-12597.

Wen L, Tang FL, Hong Y, Luo SW, Wang CL, He W, Shen C, Jung JU, Xiong F, Lee DH, Zhang QG, Brann D, Kim TW, Yan R, Mei L, Xiong WC (2011) Vps35 haploinsufficiency increases Alzheimer's disease neuropathology. J Cell Biol 195:765-779.

Williams ET, Chen X, Moore DJ (2017) Vps35, the retromer complex and Parkinson's disease. J Parkinsons Dis 7:219-233.

Zhuo L, Theis M, Alvarez-Maya I, Brenner M, Willecke K, Messing A (2001) hGFAP-cre transgenic mice for manipulation of glial and neuronal function in vivo. Genesis 31:85-94.

Zimprich A, Benet-Pagès A, Struhal W, Graf E, Eck SH, Offman MN, Haubenberger D, Spielberger S, Schulte EC, Lichtner P, Rossle SC, Klopp N, Wolf E, Seppi K, Pirker W, Presslauer S, Mollenhauer B, Katzenschlager R, Foki T, Hotzy C, et al. (2011) A mutation in Vps35, encoding a subunit of the retromer complex, causes late-onset Parkinson disease. Am J Hum Genet 89:168-175. 